Preprints of the

Max Planck Institute for

Research on Collective Goods

Bonn 2011/20

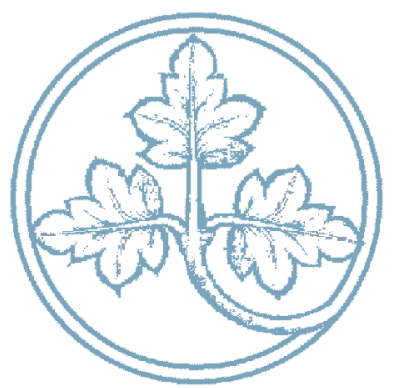

Public Debt Requirements in A Regime of Price Stability

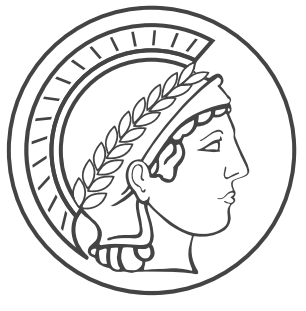




\title{
Public Debt Requirements in A Regime of Price Stability
}

\author{
Carl Christian von Weizsäcker
}

August 2011 


\author{
Carl Christian von Weizsäcker \\ Max-Planck-Institute for Research on Collective Goods \\ July 2011
}

\title{
Public Debt Requirements in A Regime of Price Stability
}

\begin{abstract}
.
The logic of this paper is based on a modernisation of Austrian capital theory as applied to a closed economy growing in a steady state. Here the philosophy is this: capital is time embodied in produced goods. In steady states, this philosophy works well as an aggregation device for an arbitrary number of distinct produced goods. The basic theorem of this approach (Section VII) is this: in a capital market equilibrium without public debt and hence in a general equilibrium without public debt the average period of production equals the average waiting period of households. Calibration of the parameters of the production sector and the consumption sector then leads to the result that the equilibrium risk free real rate of interest (Wicksell's "natural rate of interest") is negative for the OECD+China area. What distinguishes the twenty-first century from earlier times is the high life expectancy of people and the ensuing extensive average pension period. These characteristics are responsible for the high average waiting period. Only with a negative real rate of interest can the average period of production catch up with the high average waiting period.

Under price stability the risk free real rate of interest cannot become negative. Public debt causes the equilibrium risk free rate of interest to rise: the public debt period $(D)$ plus the average period of production $(T)$ equal the average waiting period $(Z)$. Thus substantial public debt is required for the goal of price stability. We thus come to a different view of public debt: it is inconsistent with the goal of a zero public debt. This different view of public debt (even apart from "Keynesian" considerations) has been introduced by Samuelson already in the year 1958. My "Austrian" capital theoretic approach allows me to show that it is the relevant view for the 21 st century.
\end{abstract}

\section{Overview of the Paper}

Part I: Verbal Argument

1. Introduction: The negative natural rate of interest problem

2. Demographics: the main reason for a negative natural rate of interest

3. The savings triangle.

4. The "deep" structure of capital supply in modern democratic societies.

5. Limits to roundaboutness of production: "thermodynamics".

6. A note on the method of model building: CIS rather than CES

7. Land

8. The meaning of price stability

9. Ponzi and all that

10. Crowding out

11. How to view public debt? Part1

a. Public debt - neither black nor white

b. The relevance of the real rate of interest

c. Capital exports and imports 
d. Measuring the "RFRRI".

e. The perception of default risk in capital markets

f. Explicit and implicit public debt

12. How to view public debt? Part 2

a. Sub-optimality of the international public debt Nash-equilibrium

b. Public debt and the balance of trade

c. Keynes and the negative natural rate of interest problem

d. Can and should capital be exported to the Third World?

e. The recent crisis

Part II A Model Based on Capital Theory: An "Austrian" Approach

I Introduction

II Marx and Leontief modernised

III The average period of production: Böhm-Bawerk modernised

IV Substitution due to changes in the rate of interest

V The consumption sector

VI Inter-temporal substitution in the household sector

VII A characteristic of capital market equlibrium

VIII. Capital Market Equilibrium with Public Debt

IX. A Böhm-Bawerkian view on the Solow model

$\mathrm{X}$ A more general approach

XI Calibration for the production sector

XII A standard model of household consumption and saving

XIII Calibration for the consumption sector

XIV The negative natural rate of interest

Summing Up 


\section{$\underline{\text { Part I: Verbal Argument }}$}

\section{Introduction: The negative natural rate of interest problem}

A large majority of commentators have explained the recent economic crisis by pointing to the mal-functioning of financial markets. Many economists have said: a low interest policy of the Fed in particular, in conjunction with the deregulation of financial markets, have led to a housing bubble and thereupon a collapse of asset prices with the consequence that the highly leveraged banks no longer trusted each other. The ensuing crisis in the real economy would have been much worse had not the governments and the central banks intervened to save most of the banks.

I do not quarrel with this analysis of many highly competent commentators, with one exception: I am not at all sure that a crisis of similar magnitude could have been avoided, if the Fed would have pursued a more restrictive policy in the early years of the decade. In this paper I want to explain why I come to this conclusion. I believe the rich countries jointly with China face a problem of incompatibility between two goals: price stability and low (ideally: zero) government indebtedness. In my opinion in a world without public debt the natural rate of interest - in the sense Wicksell used this term - would be negative. And reaching this natural rate of interest would then be incompatible with price stability. The nominal rate of interest cannot become negative - and under price stability the real rate of interest equals the nominal rate. Thus it cannot reach Wicksell's natural rate, if the latter is negative.

I do not claim to know whether the present level of public debt in the rich countries plus China is sufficient to overcome the negative natural rate of interest problem. My only claim in this paper is that a zero public debt in these countries would cause the natural rate of interest to be negative. Yet, if this claim is correct, the debate about the public debt would have to change its character. I come back to this point below.

This paper has two main parts. In the first part I describe my thoughts in words, using -I believe - a kind of reasoning economic policy makers and their advisors are familiar with: common sense economics and sociology and simple logical reasoning. In the second part I use the method of model building to derive a theoretical result. The theoretical result is the following proposition: in a closed economy without public debt and with parameter values conforming to the rich part of the world capital market equilibrium requires a negative natural rate of interest. I use and explain this result in the first part.

In the model that I develop in the second part I use ideas which come from a field of economic theory that nowadays has almost been forgotten: capital theory. It flourished in earlier decades, going back as far as Karl Marx, Eugen von Böhm-Bawerk, Irving Fisher and John Bates Clark. But its final boom (a bubble?) was in the sixties and early seventies of the twentieth century. The great names then were Paul Samuelson, Robert Solow, Joan Robinson and Piero Sraffa. At that time I myself participated in this research. I believe that the present macro-economic discussion suffers from the fact that certain insights of capital theory have been forgotten.

The sections in the first part have Arabic numbers; the sections in the second part have Roman numbers.

\section{Demographics: the main reason for a negative natural rate of interest}


Following Wicksell (1898) I define the natural rate of interest as the equilibrium real rate of interest for an economy with zero public debt. If there is public debt it is likely that the equilibrium real rate of interest is higher than the natural rate (as defined here. Alternatively one could define the natural rate as the equilibrium real rate of interest taking account of government debt. But for the purposes of this paper it is convenient to define it as I have done).

Following the tradition in capital theory but also consistent with modern macro-economics the natural rate of interest equates the supply of capital (as a stock) and the demand for capital (as a stock). One would normally expect an excess supply of capital if the actual market rate of interest is above the natural rate, and one would normally expect an excess demand for capital if the actual market rate of interest is below the natural rate.

In Wicksell's and Böhm-Bawerk's time neoclassical economists were convinced that the natural rate of interest was positive. The magnum opus of Böhm-Bawerk (1889) was written to explain why there was a positive real rate of interest. Wicksell basically followed the reasoning of Böhm-Bawerk and then investigated in detail the relation between the natural rate of interest and the "money rate of interest" as set by the central bank and generally by the financial sector. Given the parameters, as they prevailed in the late $19^{\text {th }}$ century, it was probably correct to think that the natural rate of interest was positive.

But the twentieth century has changed the relevant parameters in a dramatic way. In the rich countries the material standard of living of the median citizen has gone up by a factor ten or twenty. A large part of that rise has been consumed in the form of shorter working time. At the end of the twentieth century Europeans and North-Americans spent more time in front of a television set than on the job. Also life expectancy has risen substantially. But, at least for the last 50 years, the higher life expectancy has not led to a rise in the age at which people stop working for an income. This is one major form in which the shortening of working time has been implemented. Therefore the pension period has risen in a dramatic way. This process is still going on, and we can expect an even higher average pension life in the future. In Germany the average time a pensioner of the social security system receives his/her pension has risen from 10 years in 1970 to 17 years in 2010. Thus, the rise in the average pension time was two months per year. The corresponding average pension time 120 years ago -when Wicksell and Böhm-Bawerk were writing - was below two years.

How do people provide for the time when they no longer have an earned income from work? Traditionally, and thus at a time, when this period was much shorter, the family took responsibility for the old people. Today it is the welfare state and private liquid wealth, and only to a much lesser extent the family. Assume, for the moment, that old age provisions are done by saving money as in private life insurance. The amount of capital which would be supplied to the economy would be substantially higher than it is today. As it actually is organised, social security (including health insurance) is a pay-as-you-go system.

On the other hand, demand for capital by the production sector of the economy roughly rises in proportion to the level of production, i.e. roughly in proportion to GDP. Marx and also Böhm-Bawerk believed that there was a secular tendency towards an ever rising ratio of capital to output. Marx talked about the "organic composition of capital" in this context, which he believed would rise and rise and would cause the profit rate to decline until 
capitalism collapses. Böhm-Bawerk also thought that through time the roundaboutness of production would rise ${ }^{1}$. It did not happen.

Thus, demand for capital - as a ratio to annual production - did not rise, whereas, due to demographic reasons, "supply" did - if we thereby mean: the volume of rights to receive money in the future. I write "supply", because parts of this "supply" are the result of forced saving within a social security system. We can surmise that without social security people would have acquired a smaller amount of such rights. Whatever the form of accumulating wealth, it is the case for the rich countries plus China that private wealth (if we include social security and other pension claims for the future and if we include certain claims on health services financed by earlier rather than simultaneous contributions) exceeds the value of capital tied to the production process by far. The gap between the two magnitudes basically is made up of public debt, explicit and implicit. And this not by happenstance, but for reasons which follow from the very social order of rich societies. This will be discussed in section 4 . But before, in section 3, I point to a very simple arithmetic fact.

\section{The savings triangle.}

Imagine a hypothetical stationary and closed economy with overlapping generations of representative consumers. They start working at their lifetime zero (biological age perhaps 20 years, but for convenience I denote age by biological age minus 20). They work a years. Then they retire and live another $b$ years. They have to provide for their old age by saving. They save during their working time. Assume their wage remains the same through time. Assume they save the same amount every year until they retire. The rate of interest they get is zero. They want to save enough so as to be able to keep their level of consumption constant through their life. Assume this consumption level per year to be unity, i.e. $=1$. This then forces them to save enough to own wealth $b$ at their moment of retirement. Only then can they consume one unit per year through retirement. Given this behaviour their wealth as a function of their age is a triangle as seen in the graph 1 , below. The base line of the triangle has length $a+b$. The height of the triangle is $b$. Assuming that each annual age cohort has size one the area of the triangle gives us the wealth owned by the population of this economy. The area is, as is well known, from high-school geometry base-line times height divided by 2, hence in this case $(a+b)$ times $b / 2$. But the population of this economy is $a+b$. Thus society's wealth per person is $b / 2$, is half the period of retirement times annual consumption per person.

I use the term "average waiting period" or simply "waiting period" for the ratio between wealth of society and its annual consumption. Thus, in our simple example, the waiting period is half the period of retirement. The term "waiting period" is justified, because on average the person "waits" $b / 2$ years before she/se consumes her/his wage income. This can be seen by looking at the "time points of gravity" of wage income and of consumption expenditure of the person. The "time point of gravity" of wage income is at the middle of the wage earning period, hence it is at $a / 2$. The "time point of gravity" of consumption is in the middle of the consumption period, thus at $(a+b) / 2$. "On average" the person thus "waits" $(a+b) / 2-a / 2=b / 2$ years before she/he consumes her/his wages. It then turns out that the average wealth in society divided by annual consumption equals the "waiting period". This, as

\footnotetext{
${ }^{1}$ It can be shown that Marx' "organic composition of capital" is identical with the "average period of production", which Böhm-Bawerk introduced to measure the degree of roundaboutness of production (von Weizsäcker 1977). In this case it is the original version of the average period of production, not the modernised version introduced by me (von Weizsäcker 1971).
} 


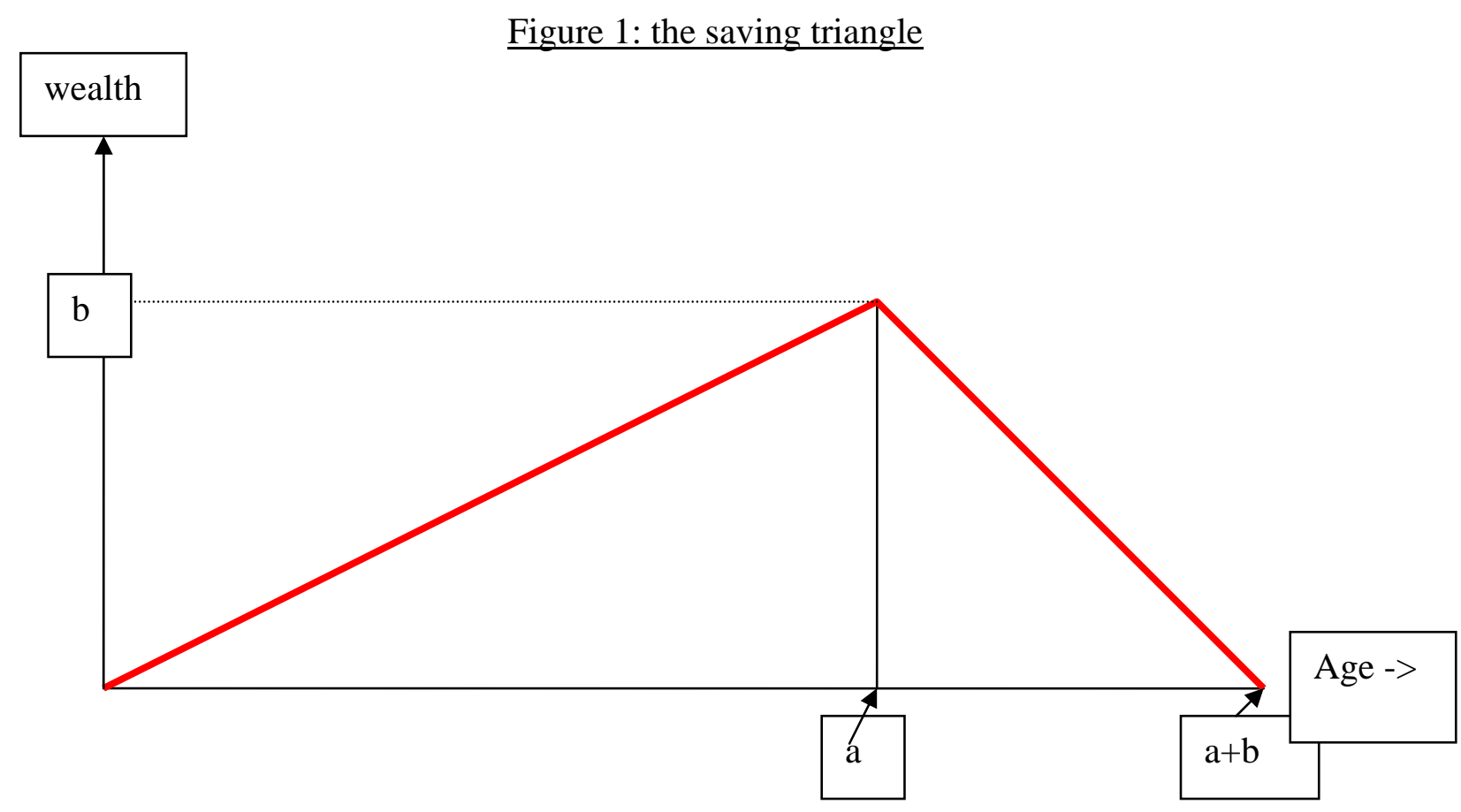

is shown in sections V and VI of this paper (second part), is a general property. The ratio of wealth to annual consumption in a society can be identified with the average waiting period in society.

\section{The "deep" structure of capital supply in modern democratic societies.}

The rapid rise of life expectancy in the rich countries to a certain extent is due to progress in medical science. But in conjunction with this scientific progress, it is also due to the generalised access of people to health services. In the rich countries there is no longer a financial access barrier to a certain decent minimum of medical services (with perhaps some exceptions for the USA). To put it the other way round: one of the main reasons for a short average life expectancy in earlier times has been that poverty with high probability lead to death. Even though it is still true that there is a positive correlation between economic condition and life expectancy it is clearly also the case that the welfare state has a strong impact on average longevity. There is then some positive feedback mechanism between the expenses of the welfare state and average longevity: the former raise longevity; and the latter by raising the pension period - raises welfare state expenses.

But this positive feedback mechanism also applies to politics. Pensioners and people who expect soon to be pensioners are voters. The rising longevity, partly due to the welfare state, raises the proportion of pensioner voters in the electorate. This again tends to raise political support for an extensive pension system. Dismantling the welfare state is not a political option. The welfare state is deeply ingrained in the structure of modern society, of modern democracy.

Modern democracies also are market economies. Historically, the capitalist mode of running the economy has turned out to be without a realistic alternative. But market economies need 
entrepreneurs. It is unthinkable that all production activities are organised in publicly traded companies. The latter's actual share in generating the value added of the production system is below one third (I would guess). Principal-agent problems of publicly traded companies are simply too large to be suitable for each and every economic production activity. (It is interesting that Marx saw publicly traded companies as a kind of forerunner of socialisation within the capitalist system. The centrally planned economy then is the extreme case of an economy plagued by principal-agent problems: and it did not work.) The market economy can only prosper if there is a sufficiently strong class of self-employed, sufficiently well-off people (in German: "selbständiger Mittelstand"), who provide the jobs for the employed. They provide the equity capital of the small and medium sized enterprises. Now, it turns out that entrepreneurs, as a rule, do not consume all their wealth through their lifetime. They tend to leave large fractions of their wealth to their children or to other heirs; frequently they give large parts of their wealth to foundations which are supposed to maintain their capital and only to spend the dividends paid out to them.

The upshot of this is that a lot of savings are kept as wealth over a very long time period and thus are not consumed for a very long time period. This period is not limited by the death date of its "originator". The "average waiting period" then is substantially larger than the one which one derives from provisions for old age only. The latter is of the order of magnitude of half the pension period, thus - given pension periods for the overall population, not just social security pensioners, of close to twenty years - close to 10 years. This then leads to a guesstimate of the average waiting period in modern societies of 12 years or more.

As I already pointed out, abolition of the welfare state is out of the question. Also, abolition of the market economy with its entrepreneurial class is out of the question. We are then more or less stuck with a will of people to provide for one's own and one's offspring's future in the order of magnitude of 12 years annual consumption - public consumption included. This then is the order of magnitude of the supply of capital.

There are, of course, policy alternatives which may be politically feasible and which may be able to contribute to a certain reduction of the "waiting period". But they cannot change the supply of capital by more than a trifle - provided the welfare of the people is maintained. (One could of course start destroying our "wealth machine", by abolishing property rights one way or the other, thereby destroying incentives to provide for the future altogether, and thereby destroying the welfare state altogether. I expect this not to happen. Nevertheless, if it did happen, the outcome would not be welcomed, except by those, who yearn for another "cultural revolution" - clearly a small minority). There exist - laudable - attempts to generate incentives to postpone the transition from work to retirement. But, given the politics of the welfare state and given, perhaps, also human biology, such postponement will at best be of an order of magnitude which compensates for further rises in longevity to be expected in the future.

Expropriating wealth either in the lifetime or after the death of the owner can be done by tax laws. But the very incentive then no longer to accumulate wealth, then no longer to become an entrepreneur and employer would severely damage employment opportunities of those who do not want to become employers. The wealth tax in the long run would be shifted to the workers by reducing real wages. Returns to equity capital before taxes would rise accordingly and thus returns after taxes would not very much have changed.

The welfare state providing for the future of workers and the need for equity capital owned by the entrepreneurial class thus are stable characteristics of modern market economies and 
at least 12 years of annual consumption is an unchangeable feature of the kind of societies we live in.

\section{$\underline{\text { 5. Limits to roundaboutness of production: "thermodynamics". }}$}

Can we expect that at sufficiently low, but still non-negative real rates of interest the roundaboutness of production will be sufficient to absorb the supply of capital equal to 12 years of annual consumption? As I show in part II of this paper - in particular section VII capital market equilibrium requires the period of production to be equal to the waiting period, both of them computed at a "reasonable" weighting system. And the demand for capital approximately equals the period of production times the annual level of consumption. Thus, the "capital coefficient" i.e. the ratio between capital used and annual consumption goods produced would have to be 12 years, which is more than double of what it actually is.

The answer to the question is: no. The actual risk-free real rate of interest in the world economy is quite low. It cannot decline much further without becoming negative. The demand for capital by the producing sector is not sufficiently interest-elastic to allow such a rise in demand for capital to occur at a still non-negative rate of interest. In my analysis of part II I develop a kind of generalised production function and then calibrate its parameters. Here I do not go into the details. One point is important, and I therefore stress it here: value added per worker as a function of different capital intensities has a finite maximum. To the extent that the low real rate of interest - in the tradition of Solow's neoclassical growth theory - reflects a low marginal productivity of capital we then can deduce that a greater capital intensity of production (i.e. a greater roundaboutness of production) cannot add much to labour productivity. Labour productivity is already near its theoretical maximum - for a given production function. Of course, technical progress may raise labour productivity beyond any known limits. But this is not our issue here.

Why is there a finite maximum of the labour productivity as a function of the degree of roundaboutness of production? The answer is: maintenance. It may be true that - but for maintenance - there always exists further potential to raise output per unit of labour, if one is prepared to invest a little more, if one is prepared for another step of "capital deepening." But there is the need for maintenance. Buildings, which represent the bulk of capital demand in the production sector (including, of course, housing) are a case in point. Buildings do need maintenance. Thus, even at a borrowing rate of interest of zero, it does not pay to let your workers use more and more space. From a certain point onwards the incremental "productivity" of workers due to an incremental availability of space is eaten up by the incremental maintenance requirements. The same, basically, is true for equipment and also for inventories.

From physics we can invoke the second law of thermodynamics: a building, a piece of equipment, some inventory lose their designed effectiveness through time due to the fact that they are physically exposed to human activity and natural forces, as everything does due to the law of rising entropy, i.e. the second law of thermodynamics. Only by activities involving an uphill fight against the second law of thermodynamics, i.e. by activities, which we collect under the general concept of "maintenance", can these pieces of capital be kept in a state so that they remain useful in the process of production.

Due to the second law of thermodynamics we should expect a maximum labour productivity at a finite level of roundaboutness. 


\section{A Note on the Method of Model Building: CIS rather than CES}

Growth theory has extensively used the Solow production function $Y=F(K, L)$. The focus was on the substitution between labour $(L)$ and physical capital $(K)$. Early on four authors introduced the constant elasticity of substitution production function (CES function) ${ }^{2}$. By assuming that the elasticity of substitute was constant it was possible to extrapolate the production function from the range in which data were available to other ranges and thus to analyse the effect of changes in the accumulation path of capital.

This procedure to assume that an important parameter was a constant even in ranges where it could not be directly measured is of course always present when scientists try to discover new natural laws. Thus, for example, Newton obtained a constant of gravitation in his explanation of planetary movements by means of the force of gravitation. The hypothesis that there is a universal law of gravitation involved the extrapolation of this gravitational constant to other, as yet unobserved circumstances.

If we accept the hypothesis that there is a finite level of roundaboutness at which labour productivity reaches its maximum then the extrapolation by means of the CES production function is inappropropriate. The CES production function has the property that the marginal productivity of capital remains positive, no matter how much roundaboutness is already involved. But for our theory on supply of and demand for capital under conditions of price stability it is quite important to know whether or not labour productivity reaches a maximum at a level of roundaboutness which is close to the actual level. Thus we cannot work with the CES production function.

Based on my "Austrian" approach I therefore have developed another concept to replace the the elasticity of substitution between labour and capital. I call it the coefficient of intertemporal substitution. It indicates the degree to which the level of roundaboutness changes in reaction to a change in the rate of interest. Details are in section IV below. I then investigate the consequences of the assumption that this coefficient of inter-temporal substitution is a non-negative constant. It turns out that this assumption leads to a generalised production function which generally has the property that labour productivity reaches a maximum at a finite level of roundaboutness. Thus the constant coefficient of inter-temporal substitution (CIS) - function is a more appropriate set-up for the questions we want to ask in this paper.

\section{$\underline{\text { 7. Land }}$}

It was Samuelson (1958), who first suggested that public debt can serve the purpose of allowing people to save beyond the investment potential of the economy. For this purpose he invented the famous theoretical device of the overlapping-generations-model. Later it was in particular Diamond's AER paper of 1965 (Diamond 1965) which developed the subject using overlapping generations and a Solow production function.

There exists a counterargument against the argument that public debt may be needed to enhance the potential of individual provision for the future. Several economists (Feldstein (1977), Homburg (1991), and others) at different times and in different form have raised this counterargument. If land is an essential input and if the quantity of suitable land is fixed then it receives a Ricardian land rent, i.e. it receives a scarcity price. As the rate of interest

\footnotetext{
${ }^{2}$ Arrow, Chenery, Minhas, Solow (1961)
} 
converges to zero the capitalised value of future land rents goes beyond any limit. Thus, at a still positive rate of interest, there is enough real capital and land available to absorb any wish of citizens to provide for the future by saving.

The logic of this counterargument is correct. And it is indeed true that there are quantitative limits for certain natural resource inputs. But there is one problematic assumption needed for this counterargument: security of property rights. If the land-owner faces the risk of being expropriated one way or another then the price of land will not go beyond any limits. One way of expropriation is by taxation. And land cannot move from one country to another to avoid taxation.

I do not discuss details here. I just want to point out that economic theory has not well developed a branch of research which I might call "the economics of insecure property rights". In this context I point to a book which I believe to be path-breaking: North, Wallis and Weingast (2009). In this book - among other things - Douglass North and his co-authors try to explain how traditional societies work, how, in particular, they cope with the problem of violence. One important component of such coping with violence is that the ruling class redistributes property among its members according to changing power balances. Insecure property rights are then of the very essence for the peaceful co-existence of people in traditional societies, i.e. in all societies of the world up to 1800 - and most of present day societies in the less developed part of the world! The transition to modern society involves the effective centralisation of the use of violence in the hands of the State (Hobbes' Leviathan). It also involves a high degree of security of property and an effective way to collect taxes. And thus, the general traditional insecurity of property is transformed into a greater security of property against encroachments by other citizens, yet a much more effective availability of that property for potential taxation.

Demographics and the welfare state - the very causes that shift the natural rate of interest into the negative - also make it very likely that property that cannot move abroad will be taxed heavily. In any case, ownership of land is as risky an ownership as other property is. The price of land must be such as to bear a (taxation- induced) risk premium. Thus, even at a real rate of interest of zero or below zero the price of land will not be large enough to fill the gap between the private supply of capital and the private demand for capital.

\section{The meaning of price stability}

The prevailing techniques of financial intermediation lead to the result that the risk-free nominal rate of interest cannot be negative. Can we think of a scheme of providing money to the economy such that there exists the possibility of a negative nominal rate of interest? Long ago this question has been discussed and proposals have been made to enable negative nominal interest rates (Silvio Gesell (1916) and others). Assume for the moment that such devices work, so that the nominal risk free rate of interest can become negative. Can the economy then exhibit simultaneously: 1 . an excess of the waiting period over the period of production at a zero rate of interest; 2 . zero public debt; 3 . price stability? In a technical sense the answer could be: yes. By a clever device à la Silvio Gesell we may find an equilibrium at a negative nominal rate of interest with a zero rate of inflation.

But, in a deeper economic sense the answer is: no. Why is price stability a goal of economic policy? We want to provide the public with the opportunity to save portions of their current income without the risk of loss, i.e. with a guarantee that the money they have saved keeps the 
same purchasing power through time. We may then reasonably define price stability as the existence of savings instruments which are not exposed to risk, in particular not exposed to the risk of loosing purchasing power. But then, under price stability, nobody in his right mind will lend at a negative rate of interest, because he/she can always earn more by using the risk free saving instrument which is available. Thus, the prevalence of price stability as defined here excludes the possibility for borrowers to borrow at a negative nominal rate of interest. The risk-free market rate of interest thus cannot be negative.

Thus, a regime like the one proposed by Silvio Gesell violates the conditions of price stability. For the person planning for the future it is in no way better than inflation. Last year, Olivier Blanchard and co-authors (Blanchard et al (2010)) suggested that monetary policy might pursue an inflation goal of, say, $4 \%$ p.a. He suggested that thereby it would be easier to overcome slumps like the most recent one by means of monetary policy alone, i.e. without fiscal stimulus. His proposal was strongly rejected by quite a few central bankers and, at least in Germany, also by the general public. This strong rejection of a pro-inflationary policy then is a sign that for many people price stability is a very important policy goal. This means that the same people also must strongly reject regimes which force people to lend at a negative rate of interest.

\section{Ponzi and all that}

A steady state equilibrium with an interest rate below the growth rate is not a general equilibrium in the usual sense of the word, as it is used in economic theory. Such a general equilibrium does not leave any arbitrage possibility for market participants. Yet, at an interest rate below the rate of growth there is a theoretical possibility of arbitrage, which economists know under the name of Ponzi games. Mr. Ponzi could borrow money at the going interest rate, serve his debt by raising it at the rate of growth of the system and always consume the difference between the annual debt increase and the annual interest payments on the outstanding debt. Thereby additional consumption would be the result; the interest rate would rise until it reaches the rate of growth of the system. At this interest rate and above it, the Ponzi game could not go on forever, because eventually Mr. Ponzí's debt would be larger than total debt in the economy. All this is well understood among economists.

For practical purposes private Ponzi- schemes can only work as long as lenders of Mr. Ponzi have not discovered that they are part of a Ponzi- scheme. Mr. Madoff's scheme of course collapsed after it was found out to be similar to a Ponzi- scheme. I do not go into the details here why such a scheme cannot work even at a stable interest rate below the benchmark rate of growth.

The only practical enduring Ponzi is the government itself. Its power of taxation resting on its exclusive power to use force to implement the laws makes it possible that its Ponzi game remains credible as long as the rate of interest on government debt remains below or at the benchmark rate of growth. This was the implicit assumption in my analysis above. It also conforms to the academic literature (Diamond (1965), von Weizsäcker (1979), Tirole (1985), Gale (1990), Blanchard and Weil (2001), Barbie, Hagedorn and Kaul (2004)).

\section{Crowding out}


If the government decides to borrow on the capital market it does of course compete with other borrowers. In this sense public debt does always crowd out other debtors. But the real question is: does public debt crowd out debtors who are important for the welfare of society?

In the preceding argument as well as in the second, more mathematical part of this paper I use the waiting period $Z$ and the period of production $T$ for a characterisation of the supply of capital and the demand for capital. The idea then is that public debt "absorbs" the excess of capital supply over capital demand at a zero real rate of interest. We may express public debt in a way which makes it easily comparable with the waiting period and the period of production. I thus express the steady state public debt in terms of the ratio between public debt and annual consumption. Let then $D$ be the public debt period: it is this ratio of public debt to annual consumption, or, to put the same thing differently, it expresses the amount of time required for consumption to be equal to the stock of public debt. The equilibrium condition would then be

For details see Part II, sections VIII and XV.

$$
Z-D=T
$$

If we work in a neoclassical model of the steady state the Golden Rule tells us that any rate of interest below the steady state rate of growth generates "dynamical inefficiency" and thus additional government borrowing, as discussed in the previous section (and as is well known in economics) does not crowd out welfare enhancing private investment. But even in the new growth theory with endogenously determined rates of growth we can expect the following: Investments forgone by public debt so that the rate of interest rises from the negative natural rate to zero are unlikely to be socially very productive. Assuming that price stability is an important welfare enhancing goal we then can conclude that welfare rises rather than declines as the real rate of interest rises from its negative "natural" value to zero. Because, as discussed above, a negative real rate of interest is inconsistent with price stability.

It is of course well known (Diamond 1965) that as long as interest on public debt is not higher than the steady state rate of growth taxes even in the steady state are not higher than they would be without public debt. Thus, to use the parameters which I apply in part II for calibration, if the Golden Rule period of production is five years and if at this Golden Rule real rate of interest of $2 \%$ per annum the waiting period is twelve years then public debt can be seven years of annual consumption before it becomes a "steady state burden" for the taxpayer.

The conventional accounting of the state budget may confuse the general public about the tax burden of the public debt. If, as is reasonably realistic, the rate of inflation is $2 \%$ per annum, if the government pays $4 \%$ interest per annum on its debt, if the government can expect $2 \%$ real growth per annum then with explicit public debt amounting to one and a half years of private and public consumption and with government consumption (i.e. government expenditure net of government interest payments, transfer payments and investments) $25 \%$ of total consumption it may look as if government could raise its consumption from $25 \%$ to 31 $\%$ of total consumption, if it were not for public debt. But in a steady state analysis this is a mistake, because in a steady state nominal debt can grow by $4 \%$ per annum which amounts to exactly those $6 \%$ of total annual consumption paid for interest.

\section{How to view public debt? Part1}


In this paper I do not make specific policy proposals which might follow from the negative natural rate of interest problem that I believe to have derived. Obviously policy proposals need to be justified by more than just a steady state analysis. Nevertheless certain conclusions concerning an appropriate view on public debt can be drawn. In this section 11 I treat the case of an economy with a single government with a view of optimising the country's own affairs taking debt activities in other countries as given. If every country acts in this way, without international agreements, then we may find a kind of public debt Nash- equilibrium. In the next section I discuss international cooperation concerning national public debt.

a. Public debt - neither black nor white. There is a large fraction of public opinion these days which considers any form of public debt as an evil. Their "philosophy" derives from the advice of prudence for private households: the less you are in debt the better for you. This philosophy may be correct for an individual who does not expect to live forever and who therefore eventually will have to pay down all debt. Assuming that all other things are equal, in particular equal private wealth, it is also correct for a government that a low debt level outside of a steady state is better than a high debt level. But, economics tells us that not all other things can remain the same, as the level of public debt changes. In a closed economy we have: If private wealth is kept constant then a higher level of public debt implies that real capital (buildings, machines etc) is smaller. This is the crowding out of private investments by public borrowing. If real capital is kept constant then more public debt must mean that private wealth is higher. Here it does not make sense to talk of crowding out. The question then is: what is the realistic scenario: that public debt crowds out real capital formation or that public debt generates additional private wealth? If it then is the case, as suggested by my analysis, that even at a real rate of interest of zero the waiting period is in excess of the period of production we may say: zero public debt means a crowding out of price stability - or, perhaps worse: it crowds out the ability of private individuals to save as much as they want under conditions of price stability.

As recent experience shows, there can be too much public debt. It would be incorrect to derive from a steady state analysis that, as long as world capital market interest rates are low, the more debt the better. This is because a single sovereign debtor does not have control over the world capital market risk-free rate of interest. And it must be prepared for deviations from the present perhaps tranquil state of affairs. From the point of view of an individual sovereign debtor it is prudent to maintain the status of a risk- free (AAA) debtor. But this in itself does not yet solve the collective negative natural rate of interest problem.

Whatever the actual state of affairs, it is useful to accept as the benchmark a well defined steady state growth path with a given public debt period D rather than a balanced budget as is done in public discussion. The balanced budget with zero incremental public debt implies that the public debt period $\mathrm{D}$ declines whenever the nominal value of private and public consumption goes up. If, as is argued in this paper, at a nonnegative real rate of interest $\mathrm{Z}$ is structurally larger than $\mathrm{T}$ and thus a positive $\mathrm{D}$ is needed to enable people to provide at their will and without risk for their own future and for the future of their offspring then the relevant benchmark is not a balanced budget but a constant public debt period $\mathrm{D}$. The question then is: what is the optimal level of a constant public debt period D?

b. The relevance of the real rate of interest. Rules for public indebtedness like the $60 \%$ of GDP rule defined in the Maastricht criteria so far do not take account of the market rate of interest. Given the negative natural rate of interest problem rules like the Maastricht rule cannot be right. Reasonable rules concerning public debt must take account the level of the market risk free real rate of interest (RFRRI). That rate is not determined domestically, but is 
a world market rate. For a small or medium sized country it can be taken as exogenously given. Common sense tells us: the higher the given risk free real rate of interest, the more restrictive fiscal policy should be.

At a risk free real rate of interest which is above the steady state rate of growth of the economy the conventional wisdom of frugality is acceptable. It then makes sense to try to reduce the debt period $\mathrm{D}$. At a risk free real rate of interest below the steady state rate of growth conventional wisdom of frugality may lead us along the wrong track. It may then be reasonable to expand the debt period $\mathrm{D}$. A fortiori this may be advisable at a risk free real rate of interest below zero.

This dependence of the optimal debt policy on the rate of interest may be all right in principle. But for a specific rule concerning the functional relation between the risk free rate of interest and the debt policy one has to take into account the uncertainty about the future real rate of interest and the future growth potential. The greater this uncertainty the weaker should be the reaction upon a change in the rate of interest. But it would be a mistake to be so fearful of uncertainty that one does not leave any room for an impact of the rate of interest on debt policy.

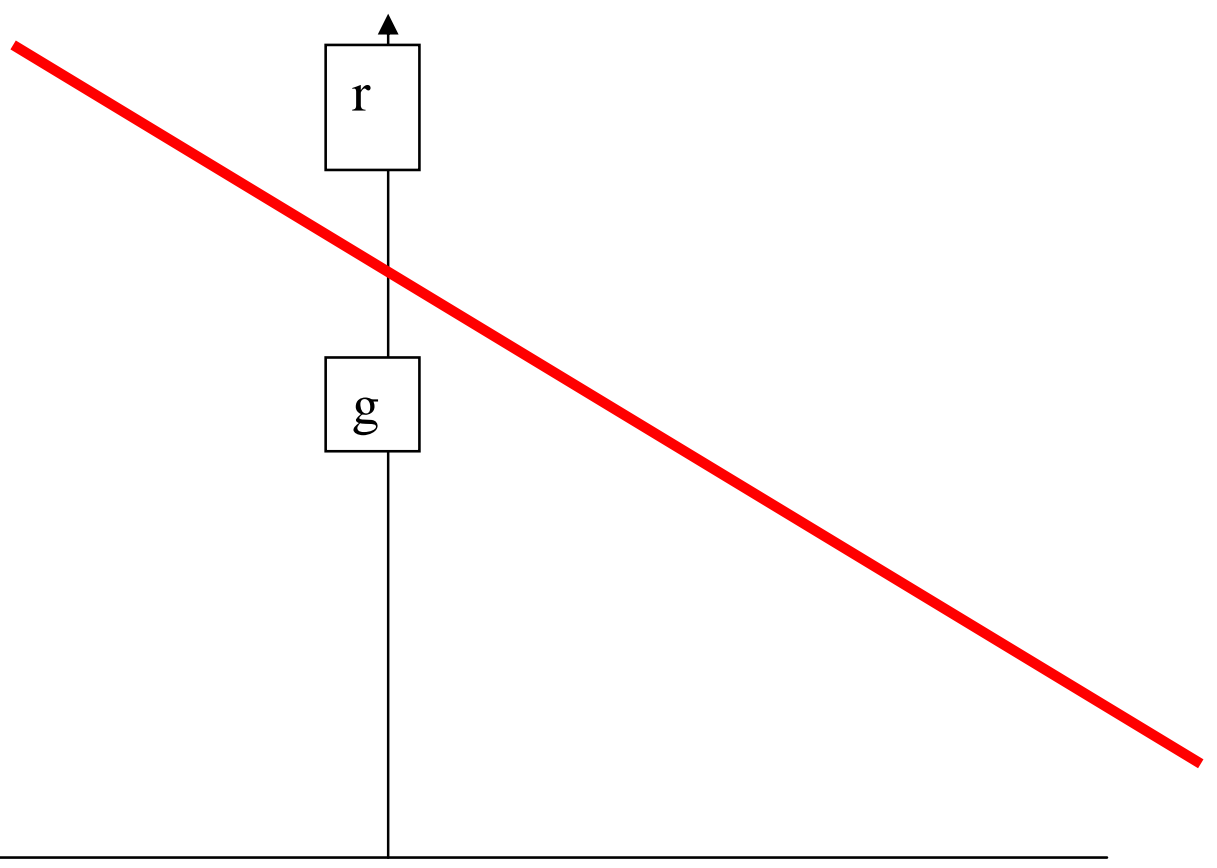

D-> 
c. Capital exports and imports. A country which is small in relation to the global economy might consider itself in a position similar to a private borrower or lender. Individuals and firms do of course take account of the market rates of interest at which they can lend or borrow. A country at large "borrows", when it imports more capital than it exports, i.e. when its balance of trade is negative. It "lends", when the opposite is true and its balance of trade is positive. A small country may not bother about the excess of the waiting period over the period of production of its own economy. It could pursue a policy of zero public debt and simply build up loans to the rest of the world (or other forms of foreign assets). But such policy may or may not be prudent. If the world market risk free real rate of interest is high, why not lend to the rest of the world and earn interest? But, if the world market risk free real rate of interest is low, say, lower than the country's own expected real rate of growth, it may not be so advisable to lend money to the rest of the world. It might then be better for domestic welfare to reduce taxes and to raise public debt, thereby reducing the lending to the rest of the world.

But, if among the countries there are net capital exporters there must be net capital importers. To the extent that a net capital importing country also is characterised by an excess of the waiting period over the period of production the net capital import must be due to public debt. For this country then the inequality $D>Z-T>0$ must hold. From the point of view of this country alone it may be prudent to reduce public debt. It then appears to be the case that not only the world market rate of interest, but also the balance of trade should influence national public debt policy. At low interest rates in particular it may be best for capital exporters to raise public debt, whereas, depending on specific circumstances, despite low risk free rates of interest it may be prudent for capital importers to reduce public deficits. A country like the USA has a currency which is also the most important world currency. It can borrow money in its own currency. Thus, the risk of default of its Federal Government is not so large even at a large negative balance of trade. On the other hand countries like Greece or Portugal which no longer have sovereignty over their currencies the risk of default of their public debt is quite substantial, as long as their balance of payments is strongly negative.

It is important to see that default risk is strongly linked with a negative balance of trade. The government of a country with a positive balance of trade will be seen by capital markets as a government which essentially borrows from its own tax- payers. If things get rougher the government could always raise taxes to pay for the debt to its own tax-payers. The government of a country with a substantial balance of trade deficit borrows large parts of its debt from people abroad who are not its tax-payers.

d. Measuring the "RFRRI". Most government debt until now is in nominal fixed interest papers. Thus, it is not easy to get reliable information on the real rate of interest, let alone the risk-free real rate of interest. We do observe a rising market section of government debt papers which insure the creditor against inflation. Although economists have talked about such insurance by means of capital market instruments for a long time, the market for such papers has grown only slowly. Many governments may be reluctant to issue such papers. But the idea seems to be catching on. Whenever this market segment has reached a certain maturity we will have reliable guidance for the equilibrium real rate of interest and then probably also for the value of the equilibrium risk free real rate of interest.

e. The perception of default risk in capital markets. Recent experience with bonds of certain European sovereign debtors are examples of potential trust instability in capital markets. If certain debtors are considered default risks the interest rates they have to pay rise and this in 
itself may make it impossible for them to avoid default. Debtor capacity to honour their obligations depends of course on the debt volume and on the interest rates they have to pay (and other things not to be discussed here in detail). Even at a risk-free real rate of interest of zero a sovereign debtor may not be able to convince the capital market that their papers are free of default risk. Potential creditors will look at indicators which they consider as good predictors of the ability and willingness of the debtor to honour its obligations. Two such indicators are likely to be the inherent growth potential of the economy and thus the tax base of the country, its balance of payments and, of course the level of its indebtedness, i.e. D, or that part of $\mathrm{D}$, which corresponds to explicit rather than implicit debt.

The perception by the capital market of default risk of a particular sovereign debtor also depends on the view potential creditors take on the public debt in general. If the view is one that really public debt is an unnecessary evil and an indication that the present generation consumes at the expense of later generations then the expectation is that real rates of interest will be high in the future - and this makes it more likely that a particular sovereign debtor will default. If the general view is that there is a negative natural rate of interest problem and that $\underline{\text { so far public debt in the world is compatible with a zero or close to zero risk-free real rate of }}$ interest then the expectation is that the risk-free real rates of interest will remain low. This then reduces the creditor's subjective probability of default of the debtor. There is then the possibility that a mistaken view on public debt ("real interest rates will be high") generates a self-fulfilling prophecy of default of sovereign debtors.

If there is uncertainty concerning the growth potential of a country this is likely to cause uncertainty about the ability of the government to honour its debt. This may severely restrict the borrowing potential of the government. One possibility to raise the borrowing potential of a State is the introduction of "GDP shares", or as Robert Shiller (Kamstra and Shiller (2010)) has coined them: "trills". The "dividend" paid on these shares is a linear (not necessarily proportional) function of the country's GDP and thus would in effect be a rising function of tax revenue. It is likely that the government's capacity to "borrow" could be raised substantially with such instruments like "GDP shares".

f. Explicit and implicit public debt. Only the smaller part of public debt is explicit debt. Implicit public debt exceeds explicit public debt. Implicit debt like provisions for future pension payments generally have the advantage (and disadvantage) that they are not traded on the international capital market. Implicit public debt also has the property that it cannot be exactly calculated. This characteristic is one major reason why official policy does not treat it as "public debt". But this may lead to grave mistakes. Public debt as a policy issue can only be handled properly if all State obligations are taken account of, also those which cannot be quantified with full precision.

A large part of implicit public debt is the subject matter of a field of research which is called "generational accounting" (Kotlikoff and Raffelhüschen (1999)). Researchers in this field try to quantify the implicit public debt arising out of future pension payments net of future contributions and of similar obligations arising from future medical treatment net of future contributions. This is a very important intellectual exercise. The problem with generational accounting so far is that their method of calculation presupposes a real rate of interest which is higher than the rate of growth of the economy. Thus generational accounting so far ignores the negative natural rate of interest problem.

I hope that generational accounting can be generalised to take account of the possibility that the risk free real rate of interest is below the expected rate of growth. This may be an 
intellectual challenge, because certain budget constraints inherent in the generational accounting approach are no longer valid.

Apart from the items taken account of in generational accounting there are other forms of implicit public debt like, for example, government guarantees for creditors of certain debtors like banks. Due to the recent financial crisis these "government CDS" have risen enormously. I am not aware of any serious attempt to quantify the implicit debt arising out of these guarantees.

There is, it seems, consensus that the implicit public debt is much larger than the explicit public debt. Frequently the reaction to this insight is: "So things are even worse. Thus, it is a fortiori important to reduce public debt." Another reaction would be this: "If public debt is so large, and has been quite large for a long time, perhaps we should have an altogether different view on the public debt in general. Perhaps public debt of the order of magnitude that we observe serves an important function. Perhaps it is the case that the optimal public debt period is as large as (or even larger than) the actual public debt period." My present paper is a contribution to this second approach.

Continuing with this approach I ask the following question: if the actual public debt period $D$ is seven years or thereabouts, if, furthermore, we cannot pinpoint the optimal level of $D$ very well, why should there be so much concern and nervousness in the capital market as the explicit public debt period rises from, say, one year to one and a half years? After all, this amounts to a rise of the public debt period from, say, 7 years to $7 \frac{1 / 2}{2}$ years, which is a rise by $7 \%$.

I do not claim to have a clear answer to these questions. I only insist that we think about public debt taking account of its negative as well as of its positive effects.

\section{How to view public debt? Part 2.}

a. Sub-optimality of the public debt Nash-equilibrium. Conventional wisdom says that there is a tendency for excessive public deficits and therefore excessive public debt. The reason given for this hypothesis is the resistance of the electorate against higher taxes and against cuts in public expenditure. Thus, politics seems to encourage excessive public debt, if compared with a reasonable standard of social welfare. This tenet of conventional wisdom has led to a movement toward constitutional provisions against public debt. Not long ago the federal constitutions of Switzerland and Germany have been amended by articles which, after a phase- in period, prohibit budget deficits. Exceptions to this prohibition only are granted for the case of crisis like circumstances. Germany tries to convince other members of the European Community and in particular other members of the Euro area to introduce similar provisions in their national laws or constitutions. Many States of the USA have similar provisions in their constitutions.

Public debt can be considered to be excessive if in a steady state growth equilibrium the RFRRI is above the rate of growth of the system. A reduction of D in this case may raise consumption per head. The Golden Rule of Accumulation or a fortiori models in which the steady state rate of growth of the economy rises with a rising share of net investment in national income point to this proposition. Also the tax burden is then higher than it would be with a smaller value for $\mathrm{D}$ : interest payments on public debt cannot be financed by deficit financing. The primary budget must be in surplus. 
If the risk-free real rate of interest generally is above the rates of growth of most countries that participate in the world capital market we may say that an incremental D of any given country exerts a kind of negative externality on other countries: the higher value of $D$ in the first country causes the world market rate of interest to rise, thereby widening the welfare loss of the public debt of the other countries. In this case the public debt Nash-equilibrium generates too much public debt in the world. There may be a case for international cooperation to agree jointly to reduce the level of the public debt period D in each country. Like the constitutional barrier against government deficits the case for such joint reduction of $\mathrm{D}$ would rest on the idea that there is a politics- induced bias towards too high deficits on a national level, which could be compensated by binding international agreements to jointly reduce the level of the public debt period $\mathrm{D}$.

On the other hand, we do not know for sure whether the RFRRI is above or below the typical rate of growth of the national economies. It could well be that it is below the typical rate of growth. We cannot exclude the possibility that national politics in conjunction with imperfections in the capital markets lead to suboptimal levels of national public debt. Thus, if the perception of the public debt is mistaken, as discussed in subsection e. of the last section, capital markets may be too pessimistic about the ability of governments to honour public debt obligations. This then may force individual States to incur lower public debt than would be optimal for that country. Capital market failure then would be a reason to cooperate internationally to raise public debt in order to achieve satisfactory high employment equilibrium between supply and demand on the international capital market. Such a situation could be particularly relevant, if conventional wisdom has not yet grasped the fact that the natural real rate of interest (defined above: the equilibrium real rate of interest in the absence of public debt) of the OECD+China area is negative, because even at a zero real rate of interest the waiting period is substantially above the period of production.

The following graph illustrates my argument. At a high world market risk free real rate of interest $r$ an incremental addition of public debt $\Delta D$ of any given country imposes a negative externality on other countries. At a low, perhaps even negative world market risk free real rate of interest $r$ an incremental addition of public debt $\Delta D$ of any given country provides a positive externality on other countries.

Figure 3: International externality of incremental public debt $\Delta D$ as a function of $r$ 


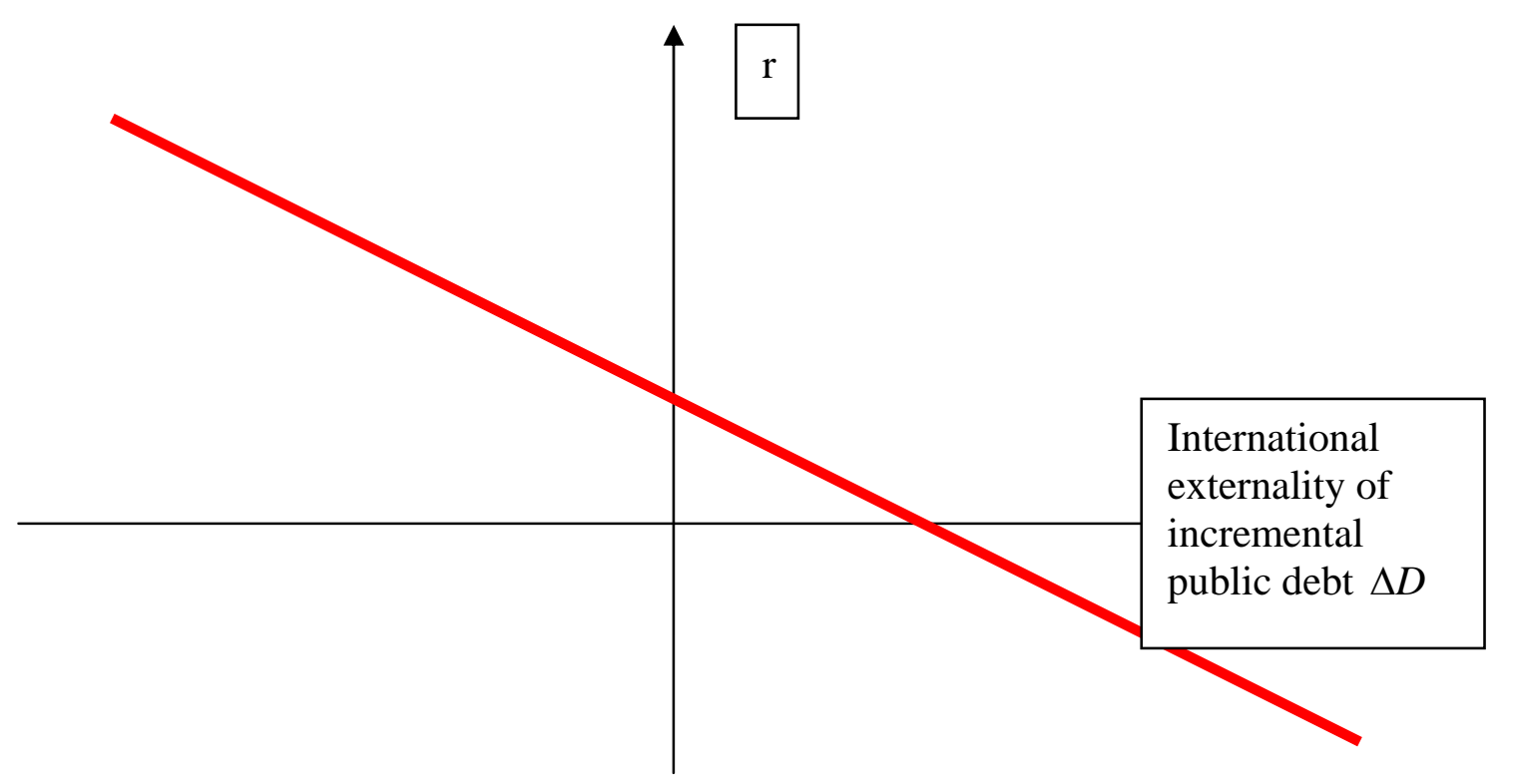

This graph can of course also be interpreted as a "demand function" for international agreements to jointly raise public debt. This demand function interpretation led me to put the independent variable on the vertical axis. In this graph the conventional wisdom is at the upper-left part of the curve, except that the conventional wisdom does not recognise the fact that it is only valid at a high RFRRI. The different view is represented at the lower right hand part of the curve.

b. Public debt and the balance of trade. As we have discussed in the last subsection, failure of politics may lead to excessive public debt and capital market failure may cause too small levels of public debt. The risk free real rate of interest is an indicator which of these opposing failures is more important. Conventional wisdom is at ease with the case of excessive public debt. If the IMF or other agencies of the collective wisdom of the different sovereign States negotiate with a particular sovereign debtor about a bridge loan, its conditionality always involves the obligation of the sovereign debtor to reduce its government expenditures and/or to raise tax revenue. In the following I therefore concentrate on the opposite case: too little public debt, in particular due to a widespread inability to raise loans for sovereign debtors on the international capital market.

In that case the risk free real rate of interest is low. There are then - as in real life today substantial differences between States concerning their ability to raise public debt. As discussed before, this ability strongly correlates with the trade balance of the countries. Capital exporters tend to have an easier time when they try to incur incremental public debt than do capital importers. Given that public debt on average is too low there is a strong case for an agreement among the States to the effect that capital exporters raise their public debt period. This would have the effect that their trade surpluses would be reduced and thus the trade balance deficits of capital importers would also be reduced. Deficit countries then can have a greater hope that their austerity programmes will work and will enable them to return to the capital market. Obviously, such international agreements to raise public debt in trade surplus countries would go with some kind of "conditionality" as regards the performance of the trade deficit countries. But we should note that, given the low RFRRI, it is in the selfinterest of surplus countries to reduce their capital exports. 
Many people in surplus countries argue against such proposals of rebalancing trade and international capital movements. They say that the trade surplus of their country is due to its superior performance in terms of international competitiveness. Given that there is a productive international competitive race among the national production systems it would be highly destructive, if countries with a good performance in terms of competitiveness were "punished" by having to give up their trade advantage. From this vantage point it is up to the deficit countries to raise their competitiveness by austerity programmes, wage reductions, opening up markets to competition etc.

But this counterargument is not correct if we are in our assumed scenario of generally insufficient public debt and low risk free real rates of interest. If the balancing burden only were on the deficit countries the world average of public debt would decline in contrast to the diagnosis that there is too little public debt.

\section{c. Keynes and the Negative Natural Rate of Interest Problem.}

The unemployment equilibrium introduced by Keynes has been intensively discussed. It turns out to be difficult to establish a general equilibrium model with underutilised production capacities. New Keynesianism has tried to overcome this problem by the introduction of devices like sticky prices etc. In this paper I have avoided going into this field of research. But the risk of unemployment due to insufficient effective demand on the macro level looms beyond the horizon of my capital- theoretic approach.

My approach in the second part of this paper is the characterisation of a full employment competitive steady state general equilibrium in terms of the waiting period and the period of production. Using calibration according to prevalent 21 st. century parameters I conclude that in such an equilibrium the natural rate of interest is negative. What is the consequence? If we stick to a full employment competitive steady state general equilibrium, we must conclude that either price stability must yield or zero public debt must yield. A third alternative would be: the full employment competitive steady state general equilibrium must yield. What would that mean? Keynesian unemployment? Chaotic dynamics, but full employment - that is: a kind of Schumpeterian macro-economics? I do not know; but my gut feeling is: if such steady state general equilibrium is not available then the utilisation of available capacities must suffer, i.e. my gut feeling is Keynesian, rather than Schumpeterian. (Moreover, as we know from his work on business cycles, Schumpeter did not cling to any full employment assumption). A deeper study of the relation between Keynesian ideas and my theory of the negative natural rate of interest might be useful; but it is not part of the present paper.

\section{d. Can and Should Capital be Exported to the Third World?}

If there is excess supply of capital in the OECD+C area, could this excess capital be exported to other parts of the world? The standard of living in many of these countries is quite low, and due to lack of capital many goods are being produced with much less roundaboutness than in the OECD countries. Yet, it is very unlikely that these Third World countries can serve as a sufficient "sink" for capital from the OECD countries and from China in a scenario without public debt.

Historical experience of the recent decades has shown that there is no positive correlation between the rate of growth of Third World national economies and their net capital imports. The success stories of Third World countries mainly are due to "export led growth" and tend to go along with net capital exports rather than net capital imports. Think of Japan, South 
Korea, Taiwan, China itself etc. The average performance record of capital imports by means of government development aid is quite discouraging. It seems that effective aid for development does not consist of capital transfers, but rather of opening up markets of the OECD countries for exports from Third World countries. Also, in most of the "Tiger States" some infant industry protectionism was involved. It was the creation of markets for their products, rather than provision of foreign capital, which caused the growth success stories of (formerly) less developed economies.

Concerning Third World countries we can point to a characteristic which we may call a restricted capacity to absorb (foreign) capital. The major cause of this characteristic is the insecurity of property rights in those countries. This insecurity leads to massive misallocations of any available capital. Foreign investors may to a certain degree be able to successfully invest into enterprises under their own control (FDI). But the skill, dexterity and industry going with such foreign direct investments is their limiting factor. In no way could FDI in Third World countries be blown up to a level which would accommodate the excess of savings over investments in the OECD $+\mathrm{C}$ area, if public debt in that area would be zero. Similarly, there is only limited capacity to absorb portfolio investments mediated by local stock markets. Also loans to public or private debtors in Third World countries are exposed to high levels of default risk.

\section{e. The recent crisis}

Imagine for a moment that in summer 2008 and in the years before the equilibrium risk free real rate of interest had been at $5 \%$ p.a. To avoid massive inflation the Fed and the ECB would have geared the market rate of interest to a level of at least $5 \%$ p.a. This, by itself, might have prevented the real estate asset bubble. Moreover, after the crash of Lehman on 15 September the two central banks would have had a lot of leeway to stabilise the financial markets by a strong reduction of interest rates. Government intervention by saving failing banks and by fiscal stimulus packages might have been unnecessary.

The lesson from this thought experiment could either be: actual interest rates were too low and thus induced the bubble and the ensuing crisis. Or the lesson could be: despite low interest rates there was little inflation. Hence the equilibrium risk free real rate of interest was low. Thus, the high employment equilibrium was precarious, because the central banks could no longer stabilise the economy in case of a financial crisis, because it was not possible to reduce the market interest rate still further. Fiscal government intervention then was called for, because of the "savings glut", which induced these low real rates of interest. My analysis in this paper provides a capital theoretic foundation for this second interpretation.

\section{$\underline{\text { Part II A Model Based on Capital Theory: An "Austrian" Approach }}$}

\section{$\underline{\text { I Introduction }}$}

Production requires capital. A firm which wants to start production needs capital to buy equipment and other inputs which are required before it can sell its output on the market. For 
any given moment of time an ongoing concern can present its balance sheet which exhibits the amount of capital tied to its operation.

Modern neoclassical economics thus has seen capital as a factor of production, as an input, so to speak. But, of course, the real goods which embody the capital (buildings, equipment, inventories) are also inputs. It would be double counting, if we would reckon them as inputs and also would reckon capital as inputs.

Modern growth theory has used the Solow production function $Y=F(L, K)$ to incorporate capital as an input. Essentially this is a one-good economy, where the good can be used also as "equipment" input for its own production. Here "capital" is a physical input in the form of the good (as equipment) to be used in the production process. The "factor price" of capital then is identified with the marginal product of capital in the production function. That is: one assumes that the marginal product of capital in market equilibrium equals the rate of interest $r$. This gives the equation $\frac{\partial Y}{\partial K}=r$ understood as an equilibrium condition. Similarly the real wage rate $w$ equals the marginal productivity of labour: $\frac{\partial Y}{\partial L}=w$. Assuming constant returns to scale we know that $Y=\frac{\partial Y}{\partial K} K+\frac{\partial Y}{\partial L} L=r K+w L$ : Factor income equals output, if factors are remunerated by their marginal products.

The Solow model (and its off-springs in the new growth economics) has been very useful in economic theory. But it ignores the problem of aggregation. In the real world capital is embodied in millions of different capital goods. Their relative prices are not fixed once and for all, but may depend on - for example - the prevailing rate of interest. Thus, the same physical capital stock may have different values depending on, say, the rate of interest.

In my work in capital theory (von Weizsäcker 1971), I used an "Austrian" approach to solve the aggregation problem. Its "philosophy" can be expressed in the following phrase: "capital is time embodied in manufactured goods". If we restrict ourselves to steady state growth equilibria, we can get results which can be seen as a solution to the aggregation problem.

For the purpose of my present analysis this approach is useful because of the theorem (to be shown in section VII) that in capital market equilibrium and hence in general equilibrium the "average period of production" must equal the "average waiting period" of households. And the "average waiting period" is a useful heuristic to understand what it is that drives the volume of capital supplied by households.

Thus, in different ways, the Solow model and my "Austrian" approach are special cases. The Solow model is the case of an economy with just one produced commodity, but it can be used outside of steady state equilibrium. My "Austrian" approach can accommodate any number of different produced commodities, but it is - so far - restricted to an analysis of steady states. In the following I proceed to develop the "Austrian" approach, as modernised by myself in my 1971 book and again further modernised in this paper.

The reason why I prefer "my" special case over "Solows" special case is given in section 6 above: in the Solow model the constant elasticity of substitution assumption (CES) does not allow a maximum labour productivity at a finite level of roundaboutness, whereas in my approach the constant coefficient of inter-temporal substitution (CIS) generally leads to such a 
maximum labour productivity at a finite level of roundaboutness. Thus, a negative "natural rate of interest" is compatible with CIS, but not with CES.

In the following sections II to VII I present my theory in a modernised form which essentially already was contained in my book on steady state capital theory. One innovation in the presentation is that I now consistently work in continuous time. From sections VIII to XVI I present new material with the following conceptual innovations: 1. the public debt period, which incorporates public debt into the "Austrian" approach, 2. the coefficient of intertemporal substitution, 3. a further analysis of the way in which the period of production and the waiting period depend on the weighting system which then leads to the public debt inequality presented in section XV. Moreover these sections present a calibration of relevant parameters, which allows me to conclude that in the OECD+ China region a non-negative equilibrium real rate of interest requires substantial levels of public debt.

\section{$\underline{\text { II Marx and Leontief modernised }}$}

Assume there are $\mathrm{n}$ produced goods. Apart from the $\mathrm{n}$ produced goods there is only homogeneous labour. We work in a model of continuous time. To begin with we ignore the possibility of substitution between different inputs. Later substitution will be introduced.

To manufacture one unit of good $j$ an input vector $a_{j}=\left(a_{1 j}, a_{2 j}, \ldots . a_{n j}\right)$ is required. In addition the amount of labour $b_{j}$ is required. Furthermore a "machine" vector $h_{j}=\left(h_{1 j}, h_{2 j}, \ldots h_{n j}\right)$ is needed. Machines depreciate, say, exponentially, but the rate of depreciation for the same kind of machine may be different depending on the use of the machine in different sectors of the economy. So we have a depreciation vector applying to the production of good $j$ which we write $s_{j}=\left(s_{1 j}, s_{2 j}, \ldots . . s_{n j}\right)$. All production processes are characterised by constant returns to scale. There is, at this stage, no technical progress. We do not separate inventories from "machines". Thus, included in the machine matrix $H$ are also the inventories required for the production process.

Let the money wage rate be $\widetilde{w}$, let the price vector of the $\mathrm{n}$ different goods be $p$. Let the rate of interest be $r$. We look at an equilibrium of the economy: prices remain constant through time. We assume perfect competition, and thus prices of outputs are equal to marginal (and, due to constant returns to scale: average) cost. Thus the price equation for good $\mathrm{j}$ is this

$$
p_{j}=\sum_{i=1}^{n} a_{i j} p_{i}+\sum_{i=1}^{n} h_{i j} s_{i j} p_{i}+r \sum_{i=1}^{n} h_{i j} p_{i}+\tilde{w} b_{j}
$$

The first term expresses the costs of current inputs per unit of output. The second term represents the costs of depreciation per unit of output. The third term is the rate of interest times the amount of capital needed per unit of output; thus it is the cost of capital. The last term is the direct labour cost per unit of output.

Written in matrix form we have

$$
p=p(A+S+H r)+\tilde{w} b
$$

Here $A$ is the non-negative input-output matrix (or Leontief matrix) with the typical element $a_{i j} \geq 0$, non-negative $S$ is the depreciation matrix with the typical element $h_{i j} s_{i j} \geq 0, H$ is the non-negative machine usage matrix with the typical element $h_{i j} \geq 0$, and $b$ is the vector of direct labour inputs with the typical element $b_{j} \geq 0$. Solving for $p$ with a given money wage rate $\tilde{w}>0$ we obtain 


$$
p=\tilde{w} b(I-A-S-r H)^{-1}
$$

The matrix $I$ is the identity matrix. Note that this solution only makes economic sense, if the matrix $A+S+r H$ is "productive", i.e. if the solution in terms of the price vector is nonnegative.

We now look at an economy which is in steady state equilibrium and grows at a rate $g$. Let $x=\left(x_{1}, x_{2}, \ldots x_{n}\right)$ be the vector of output quantities of the $n$ goods. Let $c=\left(c_{1}, c_{2}, \ldots c_{n}\right)$ be the vector of consumption goods produced and consumed. The quantity of good $i$ that is produced in equilibrium must correspond to the quantity of this good consumed plus the quantity of this good required for the production process and the growth of the system. For good $i$ we then get the equation

$$
x_{i}=c_{i}+\sum_{j=1}^{n}\left(a_{i j}+h_{i j} s_{i j}+h_{i j} g\right) x_{j}
$$

The first term under the sum sign are the inputs of good $i$ for the different outputs in the economy; the second term is depreciation of good $i$ as a capital good in the different sectors and the third term is the net investment in good $i$ in the different sectors. In matrix form we get

$$
x=c+(A+S+g H) x
$$

Hence, solving for $x$ with a given consumption vector $c$ we obtain

$$
x=(I-A-S-g H)^{-1} C
$$

We then can compute the labour requirement $L$ for this economy. We have

$$
L=b x=b(I-A-S-g H)^{-1} c
$$

Following Marx, we can compute the labour content of any given produced good $j$. For this we can set the consumption vector equal to zero at each component except component $j$, which is set equal to 1 . This we have to do with a growth rate $g=0$. (Marx -implicitly assumed a stationary economy when he developed his "labour theory of value". He was not aware of this really, since at the time economists had not yet encountered the tools of linear algebra. Marx' verbal argument in deriving the labour content of any good only was valid, if a stationary system was presupposed. On all this, see my paper with Samuelson: von Weizsäcker \& Samuelson (1971). (More generally, quite a few concepts which we use in the social sciences and in political discourse implicitly use a stationary system as a benchmark. "Income" is one of them: it is the amount of consumption you can afford, keeping wealth constant. "Sustainability" ("Nachhaltigkeit") is another: it refers to the consumption of the present generation which it can afford, if enough is left so that later generations can afford the same level of consumption. It is an interesting philosophical question, whether the human mind could develop a language using only concepts which do not rely on a stationary benchmark).

So, let $\hat{l}_{i}$ be the Marxian labour content of good $j$. Let $\hat{l}$ be the vector of labour contents of the $\mathrm{n}$ different goods. Then the equation for $\hat{l}$ reads

$$
\hat{l}=b(I-A-S)^{-1}
$$

It is the same as the price equation at a rate of interest equal to zero and a money wage rate equal to unity. 
We can compute the generalised labour content of any given good $j$ : the incremental amount of labour required if - in a steady state at time zero - the consumption vector is raised by one unit of good $j$ We may call it $l_{j}(g)$. The vector of generalised labour contents then reads

$$
l(g)=b(I-A-S-g H)^{-1}
$$

And thus it is equal to the price vector with an interest rate $r=g$ and a wage rate $\tilde{w}=1$. The total labour requirement then can also be written as $L=l(g) c$

I introduce the real wage. Assume that the commodity basket used to define the price level is some vector $\hat{q}$. Assume the consumption vector in the economy $c$ is proportional to $\hat{q}$, so that $c=C \hat{q}$ for some positive real number $C$. We may then define the real wage $w=\frac{\tilde{w}}{p \hat{q}}$. The real wage then also can be expressed as

$$
w=\frac{\tilde{w}}{p \hat{q}}=\frac{\tilde{w} C}{\tilde{w} b(I-A-S-r H)^{-1} C}=\frac{1}{b(I-A-S-r H)^{-1} \hat{q}}
$$

In the special case of there being only one produced good (the Solow model) we then have

$$
w=\frac{1-A-S-r H}{b \hat{q}}
$$

In this special case all symbols represent real numbers. Thus the real wage rate is a linear function of the rate of interest.

We may express the real wage rate $w$ in "Euro" $(€)$, if we mean a "Euro" to be a currency which has the property that one "Euro" can buy exactly one standard basket $\hat{q}$. We may then without loss of generality assume $p \hat{q}=1$.

We also can ask the question: what is the relation between the rate of growth of the system and the level of consumption today. Let $\gamma$ be the number of commodity baskets $\hat{q}$ which are consumed per man year of labour in this economy. Thus

$$
\gamma=\frac{C}{L}=\frac{C}{b(I-A-S-g H)^{-1} C}=\frac{1}{b(I-A-S-g H)^{-1} \hat{q}}
$$

Note that the formula for $\gamma$ is the same as the formula for the real wage rate, except that we have $g$ at the place where the wage formula has $r$. Thus, the trade-off between real consumption and the rate of growth is the same as the trade-off between the real wage rate and the rate of interest. The curve $w(r)$ and the curve $\gamma(g)$ are the same. This is the basic duality property of steady state capital theory.

This duality property of steady state capital theory helps us to understand the economics of the steady state of a growing economy, as will be seen below.

Figure 4: The wage-interest or consumption-growth curve 


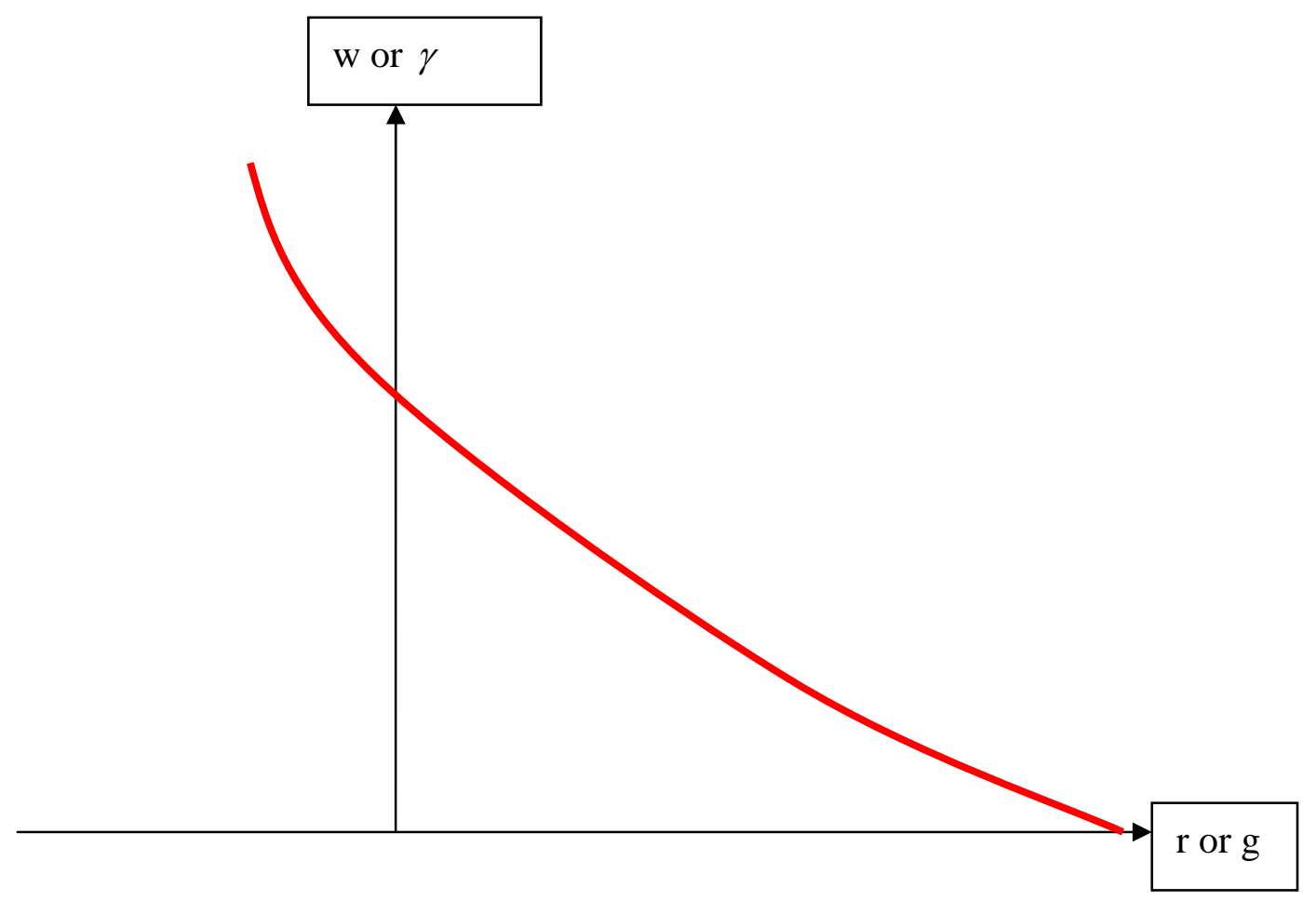

In a steady state of a growing n-good economy there is a curve called the "real wage- interest curve", which also can be seen as a trade-off between the rate of growth of the system and actual consumption per worker. This is the basic duality relation of steady state capital theory $^{\underline{3}}$.

\section{$\underline{\text { III The average period of production: Böhm-Bawerk modernised }}$}

To obtain a first intuitive grip on the concept of the period of production it may be useful to read section XVI near the very end of this paper. It presents the "point-input-point-output" model of production, which is unrealistic, but easy to understand. It is a special case of the average period of production presented in this section.

Böhm-Bawerk tried to explain why the rate of interest was positive. In a sense, what I am trying to do is the opposite: I want to show that - absent public debt - the equilibrium real rate of interest is negative. Nevertheless I can build on Böhm-Bawerk's theory of the roundaboutness of production. The greater labour productivity of a greater roundaboutness of production is the reason that a market economy exhibits roundaboutness. Böhm-Bawerk (1889) measures the degree of roundaboutness by the average period of production. It is the average time distance between original labour inputs and final outputs, i.e. outputs in the form of consumption goods. After the Second World War Böhm-Bawerk's theory was discarded for two reasons. The first reason was that a literal application of his set-up led into theoretical difficulties. The second reason was that the Solow model provided an alternative which could

\footnotetext{
${ }^{3}$ This duality property of an n-good economy was first discussed in the literature by me in a German language paper 1963 and later introduced in the English language literature by Michael Bruno in 1969 in the Review of Economic Studies. There is, of course, a related result which goes back to von Neumann (1937). There he shows that a price system which represents a rate of interest equal to the rate of growth is a characteristic of an economy which is trimmed to maximise growth and with no consumption. It is, so to speak the special case of the wage interest curve (or consumption growth curve) with a wage and consumption equal to zero.
} 
easily be treated and applied in a wide range of applications. For the issue I want to deal with in this paper I find it productive to go back to the temporal or "Austrian" theory of capital. But, to avoid the difficulties of the Böhm-Bawerkian set-up I have to modernise this set-up. I published the basic modernisation in my Steady State Capital Theory (von Weizsäcker 1971). But in this paper I go beyond that modernisation. The paper thus contains a second modernisation of Böhm-Bawerk.

First, observe that the logarithmic derivative of the wage- interest curve $w(r)$ has the dimension "time". The wage rate has the dimension "€/time". The rate of interest has the dimension " $1 /$ time". Thus, the derivative $w^{\prime}(r) \equiv \frac{d w}{d r}$ has the dimension "€". And the logarithmic derivative $\frac{w^{\prime}(r)}{w(r)}$ then has the dimension "€/€/time", i.e. it has the dimension "time". So we can write $\frac{w^{\prime}(r)}{w(r)}=-T$ where $T$ is a positive time period. What is the economic meaning of $T$ ?

The answer is: it is the (modernised) average period of production which Böhm-Bawerk used to measure the degree of roundaboutness of production.

To show this I cut up the economy in a different way than was done in the n-sector economy described in the preceding section. There the economy was cut up into production sectors, each of which produces one of the n different commodities. Now, I cut up the economy into different "virtual factories" which all look alike, except that they are of a different age.

We then have a system of "overlapping virtual factories".

The typical "virtual factory" is a fully vertically integrated production operation. It buys only labour from outside and sells only consumption goods to the outside. Thus it produces all $n$ goods itself in quantities as needed to eventually sell a vector of consumption goods to the household sector. I now describe the virtual factory which sells a constant vector stream $\hat{q}$ of consumption goods from time zero onwards.

That virtual factory existed before time zero and produced the inputs required to produce this consumption goods vector from time zero onwards. Thus, it did not buy any inputs from other firms, but produced everything itself. But it bought labour all the time to produce the goods. So for this virtual factory we have dated consumption good outputs $q(t)$ according to the following equations

$$
\begin{aligned}
& q(t)=0 ; t<0 \\
& q(t)=\hat{q} ; t \geq 0
\end{aligned}
$$

We then can compute the production vector at any given time in this virtual plant. We call it $z(t)$. Generally we have

$$
z(t)=q(t)+A z(t)+S z(t)+H \frac{d z}{d t}
$$

The first term: the consumption goods delivered to the outside. The second term: the goods needed as current inputs for the production. The third term: the production of capital goods needed to compensate for the wear and tear of the capital stock (depreciation). The last term: the addition to the capital stock needed for the growth of production. Assuming that the capital goods matrix $H$ is invertible we can write 


$$
\frac{d z}{d t}=H^{-1}(I-A-S) z(t)-H^{-1} q(t)
$$

This is a linear vector differential equation. One of its solutions gives us the production vector $z(t)$ that makes economic sense. This means it is the only solution that remains positive for every $t$ and does not converge to infinity as time goes to plus or minus infinity. We can expect that $z(t)$ remains constant for nonnegativet, because the consumption vector remains constant. For $t \geq 0$ we then have to solve the differential equation putting $\frac{d z}{d t}=0$. Thus, we have $\left.0=H^{-1}(I-A-S) z(t)-H^{-1} \hat{q}\right)$ from which follows

$$
z(t)=(I-A-S)^{-1} \hat{q}
$$

The solution of the differential equation for negative $t$ then is

$$
z(t)=\left(\exp \left(H^{-1}(I-A-S) t\right)\right)(I-A-S)^{-1} \hat{q}
$$

Here, as before, $I$ is the n-dimensional identity matrix. We want $z(t)$ to converge to zero, as $t$ goes to $-\infty$. This is the case, if the non-negative matrices $A$ and $S$ are sufficiently small, i.e. in economic terms, if the economy at large is able to produce consumption goods in a stationary state.

The dated labour inputs of the virtual factory then are determined by the equation

$$
\lambda(t)=b z(t)
$$

I now introduce market prices. I imagine that this virtual factory is part of an economy which looks like the one described above: prices are constant through time. The virtual plant has to break even. Thus, what it buys and what it sells must have the same present value. The only input it buys is labour. Hence, with a nominal wage rate $\widetilde{w}$ its outlays or costs summed over all periods and evaluated at the present value at time zero is given by

$$
\text { Outlays }=\tilde{w} \int_{-\infty}^{\infty} b z(t) e^{-r t} d t
$$

On the other hand, revenue only consists of sales of consumption goods. Thus we have

Break-even then means equality of both, hence

$$
\text { Revenue }=\int_{0}^{\infty} e^{-r t} p q(t) d t=p \hat{q} \int_{0}^{\infty} e^{-r t} d t=\frac{p \hat{q}}{r}
$$

$$
\tilde{w} \int_{-\infty}^{\infty} b z(t) e^{-r t} d t=\int_{0}^{\infty} e^{-r t} p q(t) d t=\frac{p \hat{q}}{r}
$$

Now I investigate how the real wage depends on the rate of interest. Thus, as in the preceding section, let $\hat{q}$ be the basket, which is used to compute the cost of living index. Being in a steady state, we can assume that $\hat{q}$ remains constant through time, as in this model we ignore technical progress. Thus, the real wage $w$ can be defined as $w=\frac{\tilde{w}}{p \hat{q}}$. Thereby we get the following break-even equation

$$
w \int_{-\infty}^{+\infty} b z(t) e^{-r t} d t=\frac{1}{r}
$$

Now I obtain the first derivative of the real wage with respect to the rate of interest by differentiating the break-even equation with respect to the rate of interest. I get

which can be written

$$
\frac{d w}{d r} \int_{-\infty}^{+\infty} b z(t) e^{-r t} d t-w \int_{-\infty}^{\infty} t b z(t) e^{-r t} d t=-\frac{1}{r^{2}}
$$




$$
\frac{1}{w} \frac{d w}{d r}=\frac{\int_{-\infty}^{+\infty} t b z(t) e^{-r t} d t}{\int_{-\infty}^{+\infty} b z(t) e^{-r t} d t}-\frac{1}{r}
$$

Let $T_{L}(r)=\frac{\int_{-\infty}^{+\infty} t b z(t) e^{-r t} d t}{\int_{-\infty}^{+\infty} b z(t) e^{-r t} d t}$. It is the "time point of gravity" of labour inputs in the virtual factory. Let $T_{C}(r)=\frac{1}{r}=\frac{\int_{0}^{\infty} t p q(t) e^{-r t} d t}{\int_{0}^{\infty} p q(t) e^{-r t} d t}$. It is the "time point of gravity" of consumption goods outputs in the virtual factory. We then may define the "average period of production" $T(r)$ as the difference between these two time points of gravity of outputs and inputs. The derivative of the wage rate with respect to the rate of interest then can be written in the following form

$$
\frac{w^{\prime}(r)}{w(r)} \equiv \frac{1}{w} \frac{d w}{d r}=-T(r)
$$

The percentage or logarithmic derivative of the real wage rate with respect to the rate of interest is equal to the negative of the "average period of production".

We now ask: how much capital is in the economy at large at time zero? This capital is the sum of the capital contained in the different overlapping virtual factories which are active at time zero. For any given virtual factory the capital contained in it is the excess of the present value of future consumption goods over the present value of future wage payments. As we have defined the virtual factories they extend from time $-\infty$ to time $+\infty$. Thus, a virtual factory which is active at some time is also active at time zero. But this means that any consumption good consumed in the future will be manufactured by some virtual factory which is in existence already in time zero. Thus the sum total of future sales of consumption goods by presently active virtual factories is equal to the sum total of future consumption. Similar considerations apply to future wage payments. For a rate of interest greater than the rate of growth of the system, $r>g$, we then can compute the present value of all future consumption and the present value of all future wage payments. The difference between these two present values then is the capital which is contained in the sum of all virtual factories active today. Using the symbols introduced in the last section and writing the value of consumption and of wages in terms of the standard basket $\hat{q}$ we then obtain as the present value of future consumption $\frac{C}{r-g}$. As before, $C$ is the number of consumption baskets produced today. As the system grows at a rate $g$ the discounted value of the future stream of consumption baskets is $\frac{C}{r-g}$. Similarly, the wage sum today is $w L$ and hence the present value of future wage payments is $\frac{w L}{r-g}$. The capital contained in all overlapping virtual factories then is

$$
V=\frac{C-w L}{r-g}
$$

Define $v=\frac{V}{L}$ as the capital per worker. Define $\gamma=\frac{C}{L}$ as consumption per worker. We then get

$$
v=\frac{V}{L}=\frac{\gamma-w}{r-g}
$$


We obtain the same result for $r<g$. Only, here we have to look into the past, rather the future. The capital value also can be computed as the excess of the present value of past wage payments over the present value of past income from selling consumption goods. Because $r$ is below $g$ the present value of the economy's total consumption declines with the percentage rate $g-r$ per year with rising distance of the past from the present. The same is true for wage payments and thus we obtain

$$
V=\frac{w L-C}{g-r}
$$

and

$$
v=\frac{V}{L}=\frac{w-\gamma}{g-r}=\frac{\gamma-w}{r-g}
$$

This result of course corresponds to our national accounting intuition. Net income per worker can be seen as the sum of consumption per worker $\gamma$ and net investment per worker $g v$ or as the sum of wages per worker $w$ and capital income per worker $r v$. Thus we get the equation

$$
w+r v=\gamma+g v
$$

And thus for $r \neq g$

$$
v=\frac{\gamma-w}{r-g}
$$

Going back to the preceding section we could easily show that $v$ is a differentiable function of $r$ for given $g$. Therefore we can apply L'Hôpital's rule at the point $r=g$. We get

$$
v(g)=\frac{\gamma^{\prime}(r)-w^{\prime}(r)}{1}=-w^{\prime}(r)=-w^{\prime}(g)
$$

Using now our formula derived above from the analysis of the virtual factory we can write

$$
v(g)=-w^{\prime}(g)=w(g) T(g)=\hat{c}(g) T(g)
$$

At the rate of interest equal to the rate of growth of the system the demand for capital per man year equals the wage rate times the average period of production.

But also at different interest rates we have a similar result. We know from calculus that we can find $\rho$ between $g$ and $r$ such that the following holds:

$$
w(r)=w(g)+(r-g) w^{\prime}(\rho)=\gamma(g)+(r-g) w^{\prime}(\rho)=\gamma(g)-(r-g) T(\rho) w(\rho)
$$

This leads to

$$
v(r)=\frac{\gamma(g)-w(r)}{r-g}=\frac{-(r-g) w^{\prime}(\rho)}{r-g}=T(\rho) w(\rho)
$$

Thus, there exists a notional interest rate between the growth rate of the system and the actual interest rate such that the actual demand for capital can be understood as the wage rate times the average period of production evaluated at that notional interest rate.

\section{$\underline{\text { IV Substitution due to changes in the rate of interest }}$}

I now turn to the topic of substitution as a result of a change in the steady state rate of interest. The rate of interest can be seen as a price: the price for using some capital. Or it can be seen as a parameter influencing inter-temporal relative prices. In our steady state analysis this latter view is particularly useful. If current prices of commodities are constant through time then a 
change of the rate of interest by one percentage point changes the relative (present value) price of a good available in $t$ years by a factor which is proportional to $t$. Indeed, the price ratio in terms of present values between a good available in the present and the same good available in $t$ years is given by $e^{r t}$ Differentiation of this relative price with respect to $r$ yields $\frac{\partial e^{r t}}{\partial r}=t e^{r t}$. Thus the percentage change in the relative price equals $t$. A rise in the steady state rate of interest changes relative inter- temporal prices such that the price ratio of any two goods rises in the direction of higher prices for "earlier" goods relative to prices of "later" goods. From a neoclassical perspective we thus expect demand for "later" goods to rise and for "earlier" goods to fall; and we expect the supply of "earlier" goods to rise and of "later" goods to fall.

In the production sector of the economy (viewed in the way we did in the last section in terms of overlapping virtual factories) there is demand only for labour and there is supply only of consumption goods. We thus expect a rise in the rate of interest to induce changes in the production technology such that demand for labour will be shifted forward in time and such that supply of consumption goods will be shifted backward in time. In other words, we expect the "time point of gravity" of labour demand to shift to a higher $t$ and we expect the "time point of gravity" of the supply of consumption goods to shift to a lower $t$. This then means that we expect the "average period of production" to become smaller. We expect a higher rate of interest to induce a lower level of roundaboutness in the production sector.

In the following I show that this intuition is correct.

We could discuss substitution at the level of each of the $n$ goods, and then try to get an aggregate picture. This would be cumbersome, although it does not involve any real difficulties. What I do here - and what has been done traditionally in capital theory - is to take a more macro-economic view from the very beginning. This is legitimate in a model without uncertainty and in a model which we only evaluate at steady states.

We then talk of an array of possible "production techniques" contained in a set of feasible techniques. Let this set be called "Theta" and let $\theta \in$ Theta be any technique which could be implemented. Thus the technology described in the section II can be understood to be a function of $\theta$. Thus: $A(\theta), S(\theta), H(\theta)$. We then can derive a wage-interest curve which applies, if technique $\theta$ is implemented. Thus, we write $w=w(\theta ; r)$. Also consumption per man year will depend on the technique being used. Thus, we write $\gamma=\gamma(\theta ; g)$. For any given $\theta$ the duality property of the wage-interest curve holds: for this technique it represents the consumption-growth trade-off.

Now the question arises: which technique $\theta$ out of the set of available techniques "Theta" will be implemented? Capital theory has assumed that the markets will induce firms to choose that technique which - at a given rate of interest- allows them to offer the highest wage rate. Firms need to attract workers to be able to produce. Competition among employers leads to a choice of technique which maximises the wage rate. Equilibrium in the economy will then be characterised by the following. For any given interest rate $r$ that technique $\theta(r)$ will be chosen which has the property that

$$
w(\theta(r) ; r) \geq w(\theta ; r) \text { for any } \theta \in \text { Theta }
$$

For ease of presentation I assume that we can order the techniques $\theta(r)$ in such a way that we can characterise them by the indicator $\theta(r)=r$. Thus, we can differentiate with respect to $\theta$. 
But the substitution theorem to be shown is more general and does not depend on the differentiability of $\theta(r)$ with respect to $r$. Because $\theta(r)$ maximises $w(\theta, r)$ with respect to $\theta$ for given $r$ we obtain $\frac{\partial w(\theta, r)}{\partial \theta}=0$ at $\theta=\theta(r)$.

We now differentiate $\frac{\partial w(\theta(r), r)}{\partial r}=w^{\prime}$ with respect to $r$. That is, we form the second derivative. We have

$\frac{d w^{\prime}}{d r}=\frac{\partial w^{\prime}}{\partial \theta} \frac{d \theta}{d r}+\frac{\partial w^{\prime}}{\partial r}$. This expression cannot be smaller than $\frac{\partial w^{\prime}}{\partial r}$ because of the maximisation property of $\theta(r)$. Therefore, and since $1=\frac{d \theta}{d r}>0$ we find that $\frac{\partial w^{\prime}}{\partial \theta} \geq 0$. Remember we also have $\frac{\partial w(\theta, r)}{\partial \theta}=0$ at $\theta=\theta(r)$. Let us translate this into a characteristic of the average period of production. We differentiate $T(\theta, r)=-\frac{w^{\prime}(\theta(r), r)}{w(\theta(r), r)}$ partially with respect to $\theta$ at $\theta=\theta(r)$. We get $\frac{\partial T}{\partial \theta}=-\frac{w \frac{\partial w^{\prime}}{\partial \theta}-w^{\prime} \frac{\partial w}{\partial \theta}}{w^{2}}=-\frac{\partial w^{\prime}}{\partial \theta} \frac{1}{w} \leq 0$.

The economic interpretation of this inequality is what I call the substitution theorem in capital theory: the average period of production indicates the capital requirements of the production sector of the economy. The inequality $\frac{\partial T}{\partial \theta} \leq 0$ then indicates that a change in technique due to a rise in the rate of interest induces a reduction in the average period of production, i.e. a reduction in the demand for capital.

The substitution theorem in capital theory suggests a quantitative measure of the propensity to substitute. This is similar to the elasticity of substitution known in traditional microeconomic theory. The elasticity of substitution is dimension-free. Similarly I define the coefficient of inter-temporal substitution in the following way: the coefficient of inter-temporal substitution $\psi$ is defined as

$$
\psi=\frac{\partial \frac{1}{T}}{\partial \theta}
$$

Because $\theta$ and $1 / T$ have the same dimension "one over time" $\psi$ is dimension-free. Due to the substitution theorem in capital theory the sign of $\psi$ is non-negative. For later reference it is useful to compute

$$
\frac{\partial T}{\partial \theta}=\frac{d T}{d \frac{1}{T}} \frac{\partial \frac{1}{T}}{\partial \theta}=-T^{2} \psi
$$

Even for a given technique $\theta$ the period of production $T(\theta, r)$ does depend on $r$. This is due to the fact that the "time points of gravity" of labour inputs and consumption goods outputs are computed in terms of present values. I do not think that this dependence of the measure of roundaboutness on the rate of interest is a problem. We are familiar with price and quantity indexes. They depend on appropriate weighting systems. Thus a price index presupposes a basket of quantities. To remain relevant this basket has to change if actual baskets change. Similarly a quantity index, say an output index or an input index, depends on a price vector 
with which different outputs have to be weighed. An example is "total factor productivity", where the input of factors is a quantity index with factor prices as weights. Here, in a sense, the period of production is similar to a quantity index and thus has to be constructed using an appropriate price vector.

As an example, take the one commodity case. Here, for a given $\theta$, the wage-interest curve (and equivalently the consumption-growth curve) is a straight line. Thus $w^{\prime}(r)$ is a constant, and therefore $T=-\frac{w^{\prime}(r)}{w(r)}$ rises with a rising interest rate. It approaches infinity, as the wage rate approaches zero.

The set-up of the steady state growth model, as developed here, has a side result: we get an easy proof of the Golden Rule of Accumulation for a model much more general than the Solow model. Here it is an immediate corollary of the basic duality property of steady state capital theory. Take the steady state in which the rate of interest $r$ is equal to the rate of growth $g$. Then, by the maximisation property of the chosen technique we have $w(\theta(r), r) \geq w(\theta, r) ; \theta \in$ Theta and because of $r=g$ it follows

$$
\gamma(\theta(g), g)=w(\theta(g), g) \geq w(\theta, g)=\gamma(\theta, g) ; \theta \in \text { Theta }
$$

In words: at the same rate of growth the technique chosen if the rate of interest equals the rate of growth generates more consumption than any other available technique. The intuition behind the Golden Rule of Accumulation can be understood in terms of the period of production. The period of production is an index of the degree of "roundaboutness" of production, in German, the degree to which the economy has chosen "Produktionsumwege". Now, more roundaboutness of production may have the advantage of greater labour productivity and thus more production of consumption goods. On the other hand, a greater period of production has the disadvantage that these consumption goods arrive later and thus are to be distributed among a larger population. Thus there is an optimal roundaboutness which will be implemented at an interest rate equal to the rate of growth. The two effects of a small rise in the period of production just cancel at the rate of interest equal to the rate of growth. This implies that the "marginal productivity of greater roundaboutness" in terms of the period of production at this point must be equal to $g$ to exactly compensate the marginal "dissipating" effect of a greater period of production, which - of course - is equal to $g$. But then we have shown that the "marginal productivity of greater roundaboutness" at this point $r=g$ is correctly signalled by the rate of interest $r$.

There is a of "law of demand" for the roundaboutness of production. It is the substitution theorem in capital theory: as the steady state rate of interest rises the change of technique is such that - for a given weighting system - the degree of roundaboutness of production declines. This substitution theorem in capital theory can be used to define the following (dimensionless and nonnegative) coefficient of inter-temproal substitution $\psi$

$$
\frac{\partial T}{\partial \theta}=-\psi T^{2}
$$

\section{$\underline{\text { V The consumption sector }}$}

The consumption sector is a kind of mirror image of the production sector. The latter is on the demand side of the labour market and on the supply side of the goods markets. The former is 
on the supply side of the labour market and on the demand side of the consumption goods markets. The production sector needs capital to organise roundabout production. The consumption sector supplies capital due to a pattern of labour supply and consumer goods demand which lead to a "time point of gravity" of consumption that is later than the "time point of gravity" of labour supply. The difference between these two time points of gravity may be called the average waiting period.

In the following I present a special case of the consumption sector. But the theory is much more general. I assume the representative consumer or household. We have an economy with overlapping generations. Indeed, as we do not consider uncertainty, every future or past generation is known today. Thus, we can treat each person as extending in time from $-\infty$ to $+\infty$. Of course the real person only lives from some finite date of birth to some finite date of death. Outside of her live span consumption and labour supply simply are zero. But then there is a close formal similarity with the virtual factory, which - like consumers - is not active in markets for intermediate products. In a sense, the idea of the virtual factory serves the purpose to treat production in formal analogy to consumption. So the production sector of our economy is represented by overlapping virtual factories, which all look alike, except that they differ in their age; and the household or consumption sector is represented by overlapping households, which all look alike, except that they differ in their age.

We had a zero-profit condition for the virtual factory

$$
\hat{w} \int_{-\infty}^{\infty} b z(t) e^{-r t} d t=\int_{0}^{\infty} e^{-r t} p q(t) d t
$$

Or in terms of the real wage rate

$$
w \int_{-\infty}^{+\infty} \lambda(t) e^{-r t} d t=\int_{-\infty}^{+\infty} \hat{c}(t) e^{-r t} d t
$$

Here the scalar $\lambda(t)$ is labour input and the scalar $\hat{c}(t)$ is consumption good output in terms of the number of baskets $\hat{q}$ of consumption good production. The same formal equation can be understood as a budget constraint for a representative household which consumes the consumption stream $\hat{c}(t)$ and which supplies the labour stream $\lambda(t)$. As in the case of the virtual factory the equation can be understood as an equation to determine the real wage $w$ for given labour and consumption good streams and for a given rate of interest. In the case of the virtual factory the equation determines the real wage which the factory can pay. In the case of the representative household the equation determines the wage rate the household needs to support the labour and consumption stream.

Like in the case of the virtual factory we can determine the function $w(r)$. I differentiate the budget equation with respect to $r$. This leads to

$$
w^{\prime}(r) \int_{-\infty}^{+\infty} \lambda(t) e^{-r t} d t-w(r) \int_{-\infty}^{+\infty} t \lambda(t) e^{-r t} d t=-\int_{-\infty}^{+\infty} t \hat{c}(t) e^{-r t} d t
$$


Let the time point of gravity of labour supply be defined as $Z_{L}=\frac{\int_{-\infty}^{+\infty} t e^{-r t} \lambda(t) d t}{\int_{-\infty}^{+\infty} e^{-r t} \lambda(t) d t}$. Let the time point of gravity of consumption be defined as $Z_{C}=\frac{\int_{-\infty}^{+\infty} t e^{-r t} \hat{c}(t) d t}{\int_{-\infty}^{+\infty} e^{-r t} \hat{c}(t) d t}$. Let $Z=Z_{C}-Z_{L}$ be the difference between these two time points of gravity. We call $Z$ the "waiting period". It is the average time distance between earning wages and expending them on consumption. By dividing the derivative of the budget equation by the budget itself we get

$$
\frac{w^{\prime}(r)}{w(r)}-Z_{L}=-Z_{C} \text { or } \frac{w^{\prime}(r)}{w(r)}=-Z
$$

As the rate of interest rises by one percentage point the wage required for the support of the given labour supply flow and the given consumption flow declines by $Z$ percentage points, where $Z$ is the "waiting period".

For any given pattern of labour supply flow and consumption goods demand flow its "waiting" period determines the sensitivity of the "supporting" real wage with respect to a change in the rate of interest.

We also can understand the supply of capital in terms of the waiting period. From the national accounting equations we can write

$$
y=w(r)+r v=\gamma(g)+g v
$$

and thus

$$
v=\frac{\gamma(g)-w(r)}{r-g}
$$

Also, from the mean value theorem of calculus we obtain that there exists some notional growth rate $\rho$ between $g$ and $r$ such that

$$
\gamma(g)=\gamma(r)+(g-r) \gamma^{\prime}(\rho)=w(r)+(g-r) \gamma^{\prime}(\rho)=w(r)-(g-r) Z(\rho) \gamma(\rho)
$$

This then implies

$$
v=\frac{(r-g) Z(\rho) \gamma(\rho)}{r-g}=Z(\rho) \gamma(\rho)
$$

$\underline{\text { In this sense the supply of capital can be understood as the annual consumption times the }}$ waiting period.

In the special case $r=g$ we have $v=Z(g) \gamma(g)$.

$\underline{\text { VI Inter-temporal substitution in the household sector. }}$

In a similar way as in the production sector we can analyse changes in labour supply and consumer demand due to a change in the rate of interest. We know from elementary consumer demand theory that it is useful to distinguish between the income effect and the substitution effect of a change in prices. The "law of demand", for example, applies to compensated demand only, i.e. to a reaction of demand on price changes with real income kept constant. To 
analyse substitution in this inter- temporal model we proceed the same way: we look at substitution keeping utility of the household constant. For a given level of utility $U$ we look at the set "Etha (U)" of labour-supply and consumption-demand flows which generate that level of utility. The set Etha (U) consists of elements $\eta$ each of which designates a labour-supply and consumption-demand flow generating this level of utility. For each $\eta$ we then have a real wage rate $w(\eta, r)$ which "supports" that particular labour-supply and consumption-demand flow. The corresponding budget equation reads

$$
w(\eta, r) \int_{-\infty}^{+\infty} \lambda_{\eta}(t) e^{-r t} d t=\int_{-\infty}^{+\infty} \hat{c}_{\eta}(t) e^{-r t} d t
$$

Here $\lambda_{\eta}$ and $\hat{c}_{\eta}$ refer to the particular labour-supply and consumption-demand flow designated by $\eta \in E$ tha $(U)$.

We then ask: which $\eta$ will be implemented at a given rate of interest $r$ ? So we have a function $\eta(r)$ which indicates which $\eta$ will be implemented at any given $r$. We can assume that the household tries to maximise utility for any given wage rate and interest rate. But the utility maximising labour-consumption flow has the property that it minimises the wage rate that supports any flow $\eta \in E$ tha $(U)$. In other words

$$
w(\eta(r), r) \leq w(\eta, r) \text { for all } \eta \in \operatorname{Etha}(U)
$$

For, if there were a wage rate $w<w(\eta(r), r)$ such that it supports some $\eta \in E \operatorname{th}(U)$ then, obviously, $w(\eta(r), r)$ could support a flow with higher utility than $U$, and thus the household would not have maximised utility.

I assume that we can organise the designation of work-consumption flows in such a way that it is possible to write $\eta(r)=r$. We then can differentiate $w(\eta, r)$ with respect to $\eta$ as well as with respect to $r$. (But our theory is more general: we do not need differentiability with respect to $\eta$ ).

The minimisation property of $w(\eta(r), r)$ implies that $\frac{\partial w}{\partial \eta}=0$ at $\eta=\eta(r)=r$. I now differentiate $\frac{\partial w(\eta, r)}{\partial r}=w^{\prime}(\eta, r)=-Z w(\eta, r)$ with respect to $r$. That is, we form the second derivative.

$\frac{d w^{\prime}}{d r}=\frac{\partial w^{\prime}}{\partial \eta} \frac{d \eta}{d r}+\frac{\partial w^{\prime}}{\partial r}$ This expression cannot be larger than $\frac{\partial w^{\prime}}{\partial r}$ because of the minimisation property of $\eta(r)$. Therefore and because $\frac{d \eta}{d r}=1$ we have $\frac{\partial w^{\prime}}{\partial \eta} \leq 0$. Let us translate this into a characteristic of the average waiting period. We differentiate $Z=-\frac{w^{\prime}(\eta, r)}{w(\eta, r)}$ partially with respect to $\eta$ at $\eta=\eta(r)$ and we obtain $\frac{\partial Z}{\partial \eta}=-\frac{w \frac{\partial w^{\prime}}{\partial \eta}-w^{\prime} \frac{\partial w}{\partial \eta}}{w^{2}}=-\frac{\frac{\partial w^{\prime}}{\partial \eta}}{w} \geq 0$. The economic interpretation of this inequality is what I call the second part of the substitution theorem in capital theory: the average waiting period indicates the supply of capital by the household 
sector. The inequality $\frac{\partial Z}{\partial \eta} \geq 0$ then indicates that a change in the labour-consumption flow due to a rise in the rate of interest generates an increase in the supply of capital - the utility kept constant.

There is also a duality property of the wage- interest curve of the household. For any given labour-consumption flow $\eta$ the wage- interest curve $w(\eta, r)$ has a dual interpretation in a system of a steadily growing population. The easiest way to see this is take the national accounting equations. Let $y$ be today's net income of labour and capital per year of work, let $v$ be today's wealth per year of work. Let $\gamma$ be today's consumption per year of work. We then can write

$$
y(\eta, r)=w(\eta, r)+r v(\eta, r, g)=\gamma(\eta, g)+g v(\eta, r, g)
$$

For any given $\eta$ and for $r=g$ we obtain $w(\eta, g)=\gamma(\eta, g)$. Thus the supporting wage $w(\eta, r)$ as a function of the rate of interest represents the supporting level of consumption per work unit at a rate of growth $g=r$.

This duality property allows us to show a second Golden Rule of Accumulation. We ask the question: for a given level of utility, at which rate of interest is the supporting level of consumption per unit of work the lowest? In analogy to the proof of the first Golden Rule we can write down the following:

$$
\gamma(\eta(g), g)=w(\eta(g), g) \leq w(\eta, g)=\gamma(\eta, g) \text { for any } \eta \in E \text { tha }(U)
$$

In words: the level of consumption per unit of labour in the economy supporting a given level of utility implemented at a rate of interest $r=g$ is lower than any other steady state level of consumption per unit of labour supporting the same utility level. I call this second Golden Rule of Accumulation the Samuelson Golden Rule of Accumulation, because it is contained (in a special form) in Samuelson's famous overlapping generations paper (Samuelson 1958).

One word about the intuition concerning the fact that the supporting level of consumption per unit of labour declines as the rate of growth of the population rises. This is due to the positive waiting period: individual consumption on average occurs later in the life of an individual than does the supply of labour. This must mean that the ratio of consumption to work rises with rising age. But a population with a higher growth rate is younger on average. Thus its average ratio of consumption to labour supply is smaller than that of a population with a higher average age.

There is then a second part of the substitution theorem in capital theory: as the steady state rate of interest rises the change in labour supply and consumption demand is such that the average waiting period -keeping the weighting system and utility constant - rises. We may also call this a "law of supply": keeping the weighting system and utility the same, the waiting period as an indicator for the supply of capital rises as the price of capital, the rate of interest, $\underline{\text { rises. }}$

\section{$\underline{\text { VII A characteristic of capital market equilibrium }}$}

In this section I do not provide sufficient conditions for the existence of supply-demand equilibrium on the capital market in the steady state economy. One such existence theorem is 
contained in my book Steady State Capital Theory. Here I use the preceding analysis to present an easy way to show an important characteristic of such equilibrium.

In a steady state equilibrium with an exogenously given rate of growth $g$ a certain rate of interest $r^{*}$ prevails. The equilibrium steady state rate of interest $r^{*}$ is endogenously determined. To it corresponds a certain technique $\theta^{*}=\theta\left(r^{*}\right)$. Also a certain labour-supplyconsumption demand flow prevails: $\eta^{*}=\eta\left(U^{*}, r^{*}\right)$ where $U^{*}$ is the utility of households which prevails in equilibrium. The equilibrium technique $\theta^{*}$ and the equilibrium labourconsumption flow $\eta^{*}$ must have the property that their consumption-growth curves must exhibit the same level of consumption per work unit and their wage-interest curves must exhibit the same wage rate at the equilibrium rate of interest. Let $\gamma=f^{*}(g)$ be the consumption growth curve of the equilibrium technique $\theta^{*}$. Then, of course, we also have $w=f^{*}(r)$ from the same curve $f^{*}($.$) . Let \gamma=\varphi^{*}(g)$ be the consumption growth curve which corresponds to the equilibrium work-consumption flow $\eta^{*}$. Then, of course, we also have the wage interest curve $w=\varphi^{*}(r)$. The equilibrium requires, of course, that the two curves $f^{*}$ and $\varphi^{*}$ give the same value at the argument $g$ (because the supply of consumption goods must match the demand for consumption goods) and at the argument $r *$ (because the wage rate supporting the equilibrium labour-consumption flow must be same as the wage rate actually paid by the production sector). Thus, we have the equations

$$
f^{*}(g)=\varphi^{*}(g) \text { and } f^{*}\left(r^{*}\right)=\varphi^{*}\left(r^{*}\right)
$$

This can also be written in logarithms

$$
\ln (f *(g))=\ln \left(\varphi^{*}(g)\right) \text { and } \ln \left(f *\left(r^{*}\right)=\ln \left(\varphi^{*}\left(r^{*}\right)\right)\right.
$$

We consider the function $h(r)=\ln (f *(r))-\ln \left(\varphi^{*}(r)\right)$. Obviously $\mathrm{h}(\mathrm{g})=0$ and $\mathrm{h}\left(\mathrm{r}^{*}\right)=0$.

Hence by the mean value theorem of calculus we can find $\rho$ between $g$ and $r *$ such that $0=h^{\prime}(\rho)=-T\left(\theta^{*}, \rho\right)+Z\left(\eta^{*}, \rho\right)$. Thus there exists $\rho$ with $0 \leq \frac{\rho-g}{r^{*}-g} \leq 1$ such that $T\left(\theta^{*}, \rho\right)=Z\left(\eta^{*}, \rho\right)$.

Following Böhm- Bawerk we have used the average period of production $T$ as a heuristic for the capital requirements of the production sector. In the same spirit we have seen the average waiting period $Z$ as a heuristic for the supply of capital out of the savings of households. Equality of $T$ and $Z$ thus is a heuristic for an equilibrium.

Figure 5: The two wage-interest curves in equilibrium 


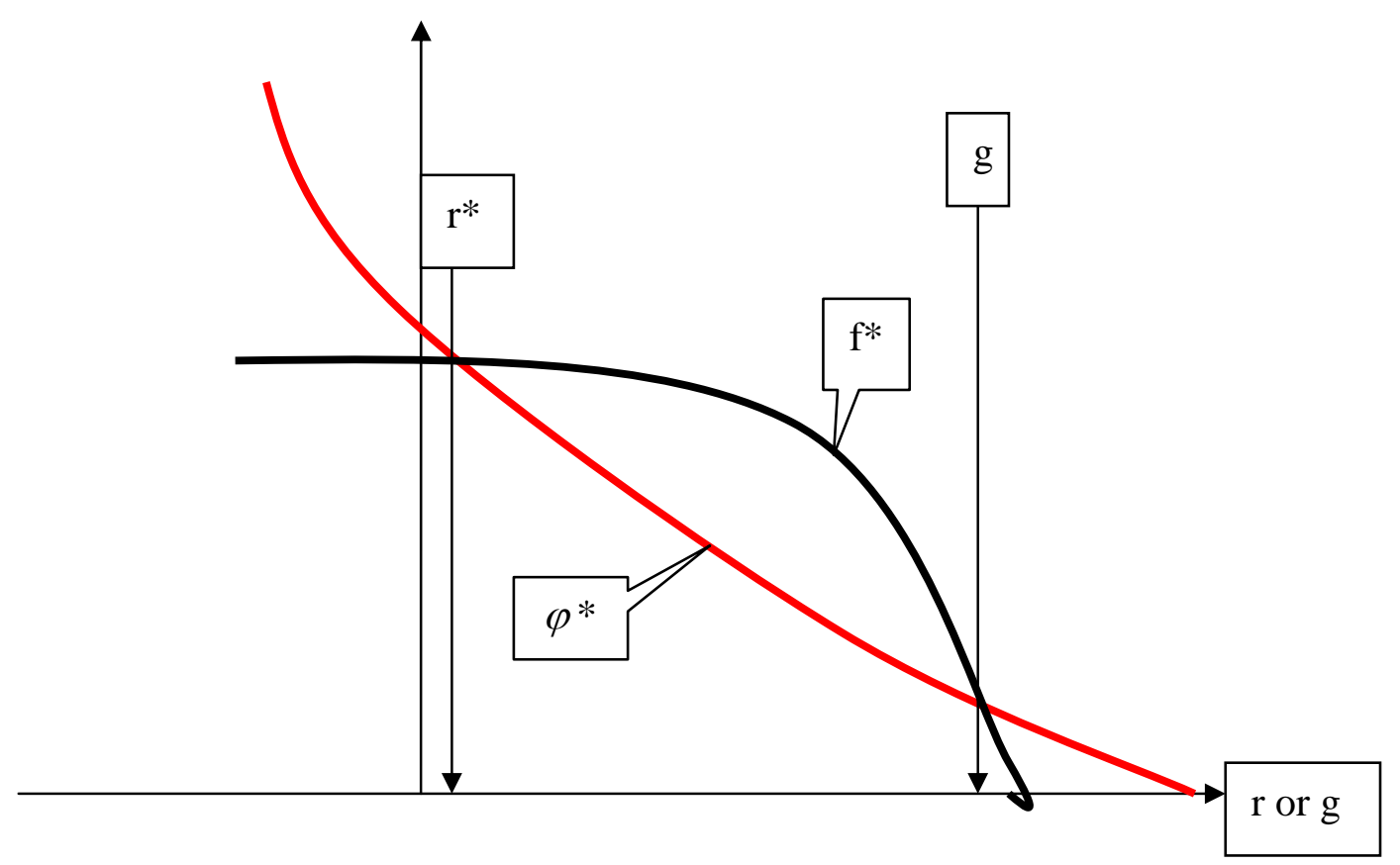

The characteristic just derived may be stated in the following

Capital Market Equilibrium Theorem: If the economy is in a steady state capital market equilibrium there exists a "reasonable" inter- temporal weighting system of labour flows and consumption flows such that with this weighting system the average period of production equals the average waiting period of consumers. By a "reasonable" weighting system I mean a weighting system which is induced by a notional rate of interest $\rho$ which lies between the actual equilibrium rate of interest and the actual steady state rate of growth.

\section{Capital Market Equilibrium with Public Debt.}

In this section I introduce public debt. As discussed in Part I, I quantify public debt in terms of the "debt period" $D$. It is the amount of time needed for consumption to equal the level of public debt. Thus public debt per man year of labour is $\gamma D$. For the government interest payments per man year then amount to $r \gamma D$. On the other hand the government obtains funds from raising the level of public debt in accordance with the growth of the system. In other words: to keep the debt period $D$ constant through time public debt has to rise by $g$, the rate of growth of the economy. Thus, in a steady state, the government's net burden of public debt per man year of labour is $(r-g) \gamma D$. Assume this net burden is paid by a tax on wages. Let $\hat{w}$ be the wage rate net of that wage tax. We then obtain

$$
\hat{w}=w-(r-g) \gamma D
$$

For a given value of $D$ we now characterise the capital market equilibrium and thus the general equilibrium. The equilibrium discussed in the last section then is the special case of $D=0$.

The easiest way to do this is to remember the equations for the supply of capital and for the demand for capital. Taking account of public debt the equation for the supply of capital $\hat{v}$ can be written 


$$
\hat{v}=\frac{\gamma(g)-\hat{w}(r)}{r-g}=\frac{\gamma(g)-w(r)+(r-g) \gamma(g) D}{r-g}=v+\gamma(g) D
$$

Here, as before, $v$ is the demand for capital from the production sector. Thus, in equilibrium the supply of capital equals the production sector demand for capital plus the public debt $\gamma(g) D$. Consider now the special case that the equilibrium rate of interest equals the rate of growth, i.e. $r=g$. We then know that $\hat{v}=Z(g) \gamma(g)$ and $v=T(g) \gamma(g)$. It then follows from the equation above that $Z(g) \gamma(g)=T(g) \gamma(g)+D \gamma(g)$ and therefore

$$
Z=T+D
$$

For $r \neq g$ I obtain further results for the relation between $Z, T$ and $D$. They are presented in section XV below.

For this section we can summarize:

If the equilibrium rate of interest $r \underline{r}$ is equal to the rate of growth $g$ then the waiting period

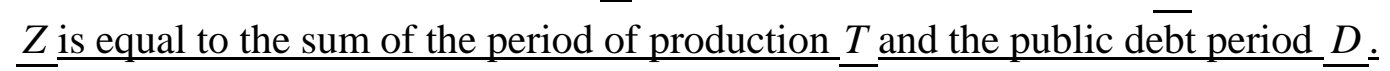

\section{$\underline{\text { IX. A Böhm-Bawerkian view on the Solow model }}$}

In this and the following sections I use the capital theory set-up to investigate the question: for a public debt level of zero, what is the value of the steady state equilibrium rate of interest? For this purpose I develop a class of production functions and later a class of utility functions in terms of the inter-temporal flows of labour and consumption goods. In this section I consider the one sector version of the general model presented in section II. I look at it from the point of view of inter-temporal capital theory as presented above. In the next section I generalise my approach.

The one sector or one commodity world is the Solow model. Here, as discussed in section II above, we have the wage-interest curve

$$
w=\frac{1-A-D-r H}{b \hat{q}}
$$

In this case all parameters $A, D, H, b, \hat{q}$ are one-dimensional vectors or matrices, i.e. scalars. Since $\hat{q}$ is the one-dimensional basket that defines the real wage, there is no loss of generality, if we put $\hat{q}=1$. For the $n$-dimensional case production vector $z(t)$ in the corresponding virtual factory of section III we obtained

$$
\begin{gathered}
z(t)=\exp \left(H^{-1}(I-A-D) t\right)(I-A-D)^{-1} \hat{q} \text { for } t \leq 0 \\
z(t)=z(0)=(I-A-D)^{-1} \hat{q} \text { for } t \geq 0
\end{gathered}
$$

For the one-dimensional case we can write this equation as follows

$$
\begin{gathered}
z(t)=e^{\left(H^{-1}(1-A-D) t\right)}\left[\frac{1}{1-A-D}\right] \text { for } t \leq 0 \\
z(t)=z(0)=\frac{1}{1-A-D} \text { for } t \geq 0
\end{gathered}
$$

The labour input flow $\lambda(t)$ then is given by 


$$
\begin{gathered}
\lambda(t)=b e^{\left(H^{-1}(1-A-D) t\right)}\left[\frac{1}{1-A-D}\right] \text { for } t \leq 0 \\
\lambda(t)=b \frac{1}{1-A-D} \text { for } t \geq 0
\end{gathered}
$$

The present value of the revenue of the virtual factory in the one-dimensional case is $p / r$. The present value of the flow of wage payments is $\frac{\hat{w} b}{(1-A-D)}\left(\frac{1}{\left(H^{-1}(1-A-D)-r\right)}+\frac{1}{r}\right)$.

This can be written as the following equation for the real wage rate

$$
w=\frac{\hat{w}}{p}=\frac{1-A-D-H r}{b}
$$

The labour flow $\lambda(t)$ in the one good case may be called an extended exponential distribution. The labour flow of the virtual factory grows exponentially up to time zero and then stays constant. The exponential growth rate $\frac{1-A-D}{H}$ is nothing but the "capital productivity" or the inverse of the "capital coefficient": the numerator is the ratio of value added to gross production, the denominator is capital tied to one unit of gross production. This makes sense: capital productivity is the rate of growth of the capital stock, if nothing is consumed, which is the case in the virtual factory before time zero. The wage rate can be seen in the following way

$$
\text { Wage rate= labour productivity - (rate of interest times capital intensity) }
$$

And labour productivity is capital productivity times capital intensity. Thus, the wage rate can be seen as

Wage rate $=$ capital intensity times (capital productivity -rate of interest)

Since the maximum rate of growth of the system is equal to capital productivity we also can write

Wage rate=capital intensity times (maximum system growth rate - rate of interest)

I now introduce substitution in the Solow model. As discussed in section IV above I define the coefficient of inter-temporal substitution $\psi$ by the equation

which leads to the differential equation

$$
\psi=\frac{\partial \frac{1}{T}}{\partial \theta}
$$

$$
\frac{\partial T}{\partial \theta}=-\psi T^{2}
$$

I now concentrate on the case that $\psi$ is a positive constant. For reasons which will become clear, I assume $\psi \neq 1$. Integration of this differential equation leads to the result

$$
T=\frac{1}{\psi} \frac{1}{\theta+a}
$$

where $a$ is a constant of integration. We now ask the question: how does the period of production change as the rate of interest changes. As discussed in section IV, we have parameterised the technique parameter $\theta$ in such a way that $\theta(r)=r$. We then obtain 


$$
\frac{d T}{d r}=\frac{\partial T}{\partial r}+\frac{\partial T}{\partial \theta} \frac{d \theta}{d r}=\frac{\partial T}{\partial r}+\frac{\partial T}{\partial \theta}=\frac{\partial T}{\partial r}-\psi T^{2}
$$

We know that, for given $\theta$, the period of production in the Solow model can be characterised as

$$
T=-\frac{w^{\prime}(r)}{w(r)}=\frac{k(\theta)}{f(\theta)-r k(\theta)}
$$

where $k$ is the capital intensity and $f$ is capital productivity times capital intensity (or output per worker). Differentiation with respect to $r$ yields

Thus we get

$$
\frac{\partial T}{\partial r}=\frac{k^{2}}{(f-r k)^{2}}=T^{2}
$$

Integration then leads to

$$
\frac{d T}{d r}=(1-\psi) T^{2}
$$

$$
T=\frac{1}{(\psi-1)} \frac{1}{(r+a)},
$$

where $a$ is a constant of integration. On the other hand, if we know the Solow production function we can find another relation between $r$ and the capital intensity $k$. This together with the relation between $r$ and $T$, enables us to find the Solow production, which corresponds to a constant coefficient of inter-temporal substitution. Let $f(k)$ be a Solow production function. We then equate the marginal productivity of capital with the rate of interest

In addition we have

$$
f^{\prime}(k)=r
$$

$$
T=-\frac{w^{\prime}(r)}{w(r)}=\frac{k}{f(k)-k f^{\prime}(k)}=\frac{1}{(\psi-1)} \frac{1}{\left(f^{\prime}(k)+a\right)}
$$

This can be written as

$$
\begin{gathered}
\left(f^{\prime}(k)+a\right)(\psi-1)=\frac{f(k)}{k}-f^{\prime}(k) \text { or } \\
f^{\prime}(k)=\frac{1}{\psi} \frac{f(k)}{k}-\frac{\psi-1}{\psi} a
\end{gathered}
$$

This linear differential equation for $f(k)$ can be integrated, and we find

$$
f(k)=B k^{\frac{1}{\psi}}-a k
$$

$B$ is a constant of integration. Indeed by differentiation we get

$$
f^{\prime}(k)=\frac{1}{\psi} B k^{\frac{1-\psi}{\psi}}-a=\frac{1}{\psi k}\left(B k^{\frac{1}{\psi}}-a k\right)-\frac{\psi-1}{\psi} a=\frac{1}{\psi} \frac{f(k)}{k}-\frac{\psi-1}{\psi} a
$$

We now distinguish between case I: $\psi>1$ and case II: $0<\psi<1$

Case I: To be economically meaningful (diminishing marginal returns to capital), we have to assume that the constant of integration $B$ is positive and the constant of integration $a$ is nonnegative. A constant coefficient of inter-temporal substitution $\psi>1$ then implies that the Solow production function is a Cobb-Douglas function minus a term which is linear in $k$. The latter term may be zero. We may interpret the Cobb-Douglas term as gross output per worker and the linear term as (exponential) depreciation.

In case I the constant capital elasticity of gross output is the inverse of the inter-temporal coefficient of substitution. At first sight this inverse relation between the coefficient of inter- 
temporal substitution and the capital elasticity may be surprising. But, as we shall see further down, it can be easily understood, when we calibrate the model and thereby grasp the interplay between the Cobb-Douglas term and the linear term of the production function.

Case II: $0<\psi<1$. In that case diminishing marginal returns to capital imply that both, $B<0$ and $a<0$. The production function then may be written as $f(k)=\bar{a} k-\bar{B} k^{\frac{1}{\psi}}$ with $\bar{a}=-a>0$ and $\bar{B}=-B>0$. It is no longer a variant of the Cobb-Douglas production function.

We note that with the exception of the Cobb-Douglas function without depreciation term in both Cases the function $f(k)$ reaches a finite maximum at some finite value of $k$.

We then see that a constant coefficient of intertemporal substitution leads to a class of Solow production functions which are different from the CES functions traditionally used in the literature. This class of production functions (with one exception) has the property that net production per unit of labour $f(k)$ reaches a finite maximum at a finite value for $k$.

\section{$\underline{X \text { A more general approach }}$}

The approach taken in my analysis is quite general, as long as we stick to steady states. In the $n$ goods case the number of parameters describing the technology is of the order of magnitude of $n^{2}$. If, for example, $n=1000$ the number of technology parameters (not counting substitution) is greater than $3^{\prime} 000^{\prime} 000$. For purposes of application calibration of the model is necessary - and there we must reduce the model to a small number of parameters to be calibrated. Here I propose a generalisation of the Solow model which adds only one parameter.

In the Solow model there is a one-to-one relation between a technique $\theta$ and the capital intensity $k$. The corresponding wage interest curve $w=f(k)-k r$ then is linear - keeping $k$ constant. The generalisation now consists in the introduction of a parameter $\beta$ so that the wage interest curve is

$$
w=(f(\theta)-r k(\theta))^{\beta+1}
$$

Here $k$ no longer is identical with the capital intensity of production. For the parameter $\beta$ we have the following constraint: $-1<\beta$. Thus $\beta$ can be negative or positive. $\beta=0$ corresponds to the Solow model. A positive value of $\beta$ means that the wage- interest curve is convex: its second derivative is positive. A negative value of $\beta$ means that the wage- interest curve is concave: its second derivative is negative.

Without going into the details I simply state the relation between the parameter $\beta$ and the time flow of labour inputs in the virtual factory. The labour flow of the virtual factory is

$$
\lambda(\tau)=\bar{\lambda} \tau^{\beta} e^{-\alpha \tau}, \tau>0
$$

Here $\tau=-t$ is the time distance between that labour input and the beginning of consumption goods production. $\bar{\lambda}$ is a constant, $\beta$ is the parameter showing up in the wage-interest curve, and $\alpha=\frac{f(\theta)}{k(\theta)}$ is the maximum rate of growth the production system can achieve - and 
therefore, due to the duality property of the wage- interest curve, the maximum rate of interest the system can pay: i.e. the zero-wage interest rate.

The labour flow of the virtual factory then can be seen as an extended Gamma distribution: a Gamma distribution up to time point zero, a constant from there-on.

I now turn to the subject of inter-temporal substitution. I assume the coefficient of intertemporal substitution to be a constant $\psi$. Thus, as before,

$$
\frac{\partial T}{\partial \theta}=-\psi T^{2}
$$

Moreover, due to $T=-\frac{w^{\prime}}{w}=\frac{(\beta+1)(f(\theta)-r k(\theta))^{\beta} k(\theta)}{(f(\theta)-r k(\theta))^{\beta+1}}=\frac{(\beta+1) k(\theta)}{f(\theta)-r k(\theta)}$ we find

$$
\frac{\partial T}{\partial r}=-\frac{-(\beta+1) k(\theta)^{2}}{(f(\theta)-r k(\theta))^{2}}=(\beta+1) T^{2}
$$

We then can derive the differential equation

$$
\frac{d T}{d r}=\frac{\partial T}{\partial r}+\frac{\partial T}{\partial \theta}=(\beta+1-\psi) T^{2}
$$

Assuming $\psi-\beta-1 \neq 0$, integration leads to

$$
T=\frac{1}{(\psi-\beta-1)} \frac{1}{(r+a)}
$$

Here $a$ is a constant of integration. As economists we are only interested in cases in which the average period of production $T$ is positive. Thus, we have to distinguish two cases (as in the discussion of the Solow model).

Case I: $\psi-\beta-1>0$. As we are particularly interested in the situation $r=0$ we then have to assume that $a$ is positive. We see that the average period of production rises as the rate of interest falls.

Case II: $\psi-\beta-1<0$. As we are particularly interested in the situation $r=0$ we then have to assume $a$ to be negative. We then could write

$$
T=\frac{1}{(\beta+1-\psi)} \frac{1}{(\bar{a}-r)} \text { with } \bar{a}=-a>0
$$

This together with $T>0$ implies that we only can consider an economically meaningful range for the interest rate below $\bar{a}$, i.e. $r<\bar{a}$. The average period of production then falls as the rate of interest falls.

There is Case III: $\psi-\beta-1=0$. In that case our differential equation tells us that the average period of production remains constant across different steady state rates of interest. Here the $T$-raising effect of a rising interest rate due to the change in the weighting system is just compensated by the $T$-lowering effect of a rising interest rate due to inter- temporal substitution.

The wage- interest curve of Case III is perhaps of some special interest. Here I mean the wage-interest curve is the "envelope" of all wage- interest curves pertaining to different techniques. Let $w^{*}(r)=w(\theta(r), r)$ be this envelope. In the case of Case III the period of 
production along $\mathrm{w}^{*}(\mathrm{r})$ is a constant and thus $\frac{d \log \left(w^{*}(r)\right)}{d r}=-T$ implies $\log \left(w^{*}(r)\right)=\log w^{*}(0)-r T$ or $w^{*}(r)=w^{*}(0)^{-r T}$ with a constant $T$. Thus -formally - the wage rate is defined for any positive or negative rate of interest. But, in reality, there are shrinking constraints to the capital stock of the economy which have not been taken account of in our analysis. This means, employers cannot really pay a money wage rate so high that gross revenue is insufficient to pay the wage. Thus part of the wage would have to be paid by transfer of ownership of slices of capital equipment.

A note on technical progress. We know from growth theory that production models without technical progress can be carried over to the case of Harrod-neutral technical progress. Harrod-neutral technical progress works like a steady enhancement of the labour force. We thus can claim our results also for the case of Harrod-neutral technical progress.

Also for a more general model than the Solow production function can we evaluate the consequences of a constant coefficient of inter-temporal substitution. The period of production is a reasonably simple function of the steady state rate of interest. In Class I of the cases $(\psi>\beta+1$ )the period of production rises as the rate of interest falls. In Class II of the cases $(\psi<\beta+1)$ the period of production falls as the rate of interest falls.

\section{$\underline{\text { XI Calibration for the production sector }}$}

I am interested in the location of the capital market equilibrium in terms of the rate of interest. As discussed in the first part of the paper, price stability makes it impossible to have a negative real rate of interest. Thus, assuming price stability, the lowest achievable real rate of interest is the zero rate. I therefore calibrate the model by comparing a steady state with a realistic rate of growth and an interest rate equal to that growth rate with a state of affairs in which the rate of interest is equal to zero. I am particularly interested in the period of production, because my capital market equilibrium theorem derived above in section VII tells us that equilibrium only can be achieved if a reasonably computed period of production and a reasonably computed waiting period of households are equal.

For my calibration I look at an economy which grows at $2 \%$ per annum and which has a ratio of net investments to (private and public) consumption of $10 \%$. These two values are representative for the rich economies of the world. Assume then further that the actual risk free real rate of interest is equal to the growth rate. This assumption is not far off the mark. AAA-rated 10 year government bonds trade at market interest rates which generally are not higher than the rate of inflation plus $2 \%$. The results of the calibration would even more strongly support my main point of a negative equilibrium rate of interest, if the benchmark interest rate would be lower than assumed here.

Here is again the formula derived in the last section

$$
T=\frac{1}{(\psi-\beta-1)} \frac{1}{(r+a)}
$$

In the benchmark state of an interest rate equal to the growth rate, a net investment ratio (relative to consumption) of $10 \%$ and an annual growth rate of $2 \%$ the period of production $\mathrm{T}$ is five years. In this benchmark state, as shown above in section III, the period of production equals the capital/consumption ratio, and thus the net investment ratio equals the period of 
production times the growth rate. This serves to calibrate the constant of integration $a$ as a function of $\psi$ and $\beta$. For any given $\psi$ and $\beta$ and the ensuing calibration of $a$ we then can compute the period of production that applies at an interest rate of zero. The following table gives the results for $\psi$-values of 2, 3 and 4 and for $\beta$-values of -.5 (concave wage interest curve), 0 (Solow-production function - linear wage-interest curve or line), and 1 (convex wage interest curve).

Table 1: $\mathrm{T}$ at $\mathrm{r}=0 \%$ with reference $\mathrm{T}=5$ at $\mathrm{r}=2 \%$

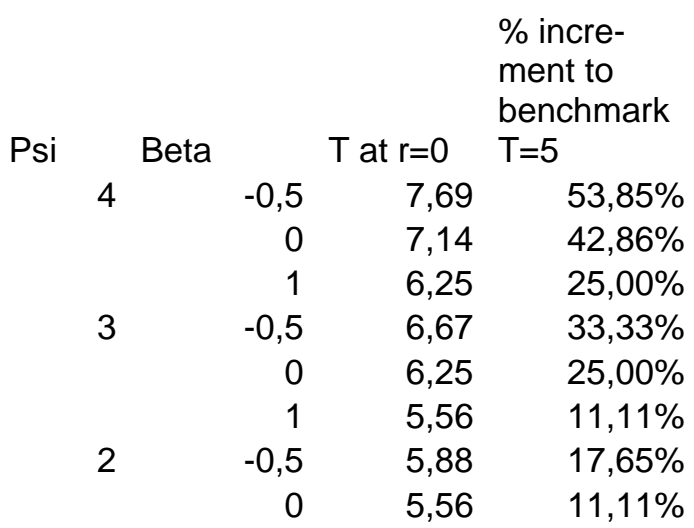

Note that I only have considered combinations of $\psi$ and $\beta$ so that $\psi-\beta-1>0$. This is Case I treated in the last section. Case II implies, as discussed in the last section, that the period of production at $r=0$ is lower than in the benchmark state.

The $\beta$-values used in Table 1 cover the realistic range of values for this parameter. For $\beta$ to equal -.5 the early production stages of the economy need to be substantially more capital intensive than the later ones. For $\beta=1$ the earlier production stages need to be substantially less capital intensive than the later ones. My guess is that $\beta$ is negative, but substantially above -0.5 .

The coefficient of inter- temporal substitution $\psi$ is unlikely to be larger than 4 . As already discussed, in the case of the Solow model $\psi$ is the inverse of the capital elasticity of production in the Cobb-Douglas part of the Solow production function compatible with a constant $\psi$-value. From any "growth accounting" studies I am aware of nobody claims that the labour elasticity of production (before depreciation) is above $75 \%$.

We may then be on the safe side to conclude that the upper bound of the average period of production at an interest rate equal to zero is 8 years.

$\underline{\text { XII A standard model of household consumption and saving. }}$

I now describe a model of the representative household. It is standard in its set-up. It will then be used for calibration. Out of this calibration results an estimate for the waiting period, i.e the supply of capital in this economy. The result is that in all likelihood even at a real rate of interest of zero the waiting period is substantially larger than the period of production.

The representative household in this overlapping generations model lives (as a grown up citizen with appropriate schooling behind her) $\hat{a}+\hat{b}$ years. She enters the labour force at time 
zero, and remains in the labour force for $\hat{a}$ years. After that she enjoys $\hat{b}$ years of retirement. To keep things simple, I assume that $\hat{a}$ and $\hat{b}$ are exogenously given. In a more sophisticated model inspired by demographics one would determine the retirement age, the life expectancy, the training and education endogenous - and one would further specify age dependent preferences for consumption goods including publicly financed consumption goods like health care. Also provisions for different risks could be introduced. I believe I can dispense at this time with all this more realistic modelling, because as an upshot of all these added complexities my thesis will only be strengthened. There is, of course, one important fact that reduces the propensity to save: it is the insecurity of property. If this insecurity is great for any kind of feasible form of saving then the answer might be: forego providing for the future and increase your present consumption. "Apres nous le déluge". But this insecurity of property is neutralised in our theoretical exercise, because I assume that there is price stability in the sense that people can, if they wish, save in the form of risk-free nominal assets. See section 8 above in Part I.

The representative person then supplies one unit of labour per year, as long as she has not yet reached retirement age. Given the real wage $w$ the present value at time zero of cumulative wage income is $w \int_{0}^{\hat{a}} e^{(g-r) t} d t=w \frac{1-e^{(g-r) \hat{a}}}{r-g}$. Here $g$ is the rate of growth of wages, which we identify with the rate of growth of the economy. The person consumes so as to maximise a utility integral from time zero to time $\hat{a}+\hat{b}$. The utility at time $t$ is given by the expression $u(\hat{c}(t))=\frac{\hat{c}^{1-\mu}}{1-\mu}$. Here $\mu$ is the parameter indicating the strength of the law of diminishing marginal utility traditionally associated with the degree of relative risk aversion. The consumer thus maximises the utility function

$$
U=\int_{0}^{\hat{a}+\hat{b}} \frac{\hat{c}(t)^{1-\mu}}{1-\mu} d t
$$

The budget constraint is

$$
\int_{0}^{\hat{a}+\hat{b}} e^{-r t} \hat{c}(t) d t=w \frac{1-e^{(g-r) \hat{a}}}{r-g}
$$

The maximisation problem has been solved by calculus of variations methods long ago. I simply refer to the heuristic: the marginal utility of consumption must be in proportion to the present value of one unit of consumption. Thus, we know that there exists $\bar{c}$ such that

$$
\hat{c}(t)^{-\mu}=\bar{c} e^{-r t}
$$

This implies an annual growth rate of consumption of $\frac{r}{\mu}$. Consumption thus is

$$
\hat{c}(t)=\hat{c}(0) e^{\frac{r}{\mu} t} \text { with } \hat{c}(0) \text { the initial value of consumption. }
$$

The budget constraint then can be written

$$
\text { Budget }=\hat{c}(0) \mu \frac{1-\exp \left(-\frac{(\mu-1) r}{\mu}(a+b)\right.}{(\mu-1) r}=w \frac{1-\exp (g-r) a}{r-g}
$$

The budget equation determines the value of $\hat{c}(0)$. 
The waiting period can be computed by integrating the following expressions. For the further analysis this computation is not necessary. For illustrative purposes we compute it in two special cases. The waiting period is the difference between the time point of gravity of consumption and the time point of gravity of labour supply. Thus we get in this model

$$
Z=Z_{C}-Z_{\lambda}=\frac{\hat{c}(0) \int_{0}^{\hat{a}+\hat{b}} t e^{r t \frac{\mu-1}{\mu}} d t}{\hat{c}(0) \int_{0}^{\hat{a}+\hat{b}} e^{r t \frac{(\mu-1)}{\mu}} d t}-\frac{w \int_{0}^{\hat{a}} t e^{g-r) t} d t}{w \int_{0}^{\hat{a}} e^{(g-r) t} d t}=\frac{\int_{0}^{\hat{a}+\hat{b}} t e^{-r t} \hat{c}(t) d t}{\text { Budget }}-\frac{\int_{0}^{\hat{a}} t e^{-r t} w(t) d t}{\text { Budget }}
$$

For the purpose of illustration here are two special cases. Assume, first, that the rate of growth of wages is zero and the rate of interest is zero. Then $\hat{c}(t)$ is stationary. The same is true for wage income as long as the person is part of the labour force. The time point of gravity of work then is $\frac{\hat{a}}{2}$. The time point of gravity of consumption then is $\frac{\hat{a}+\hat{b}}{2}$. The waiting period then is $\frac{\hat{b}}{2}$, i.e. half the pension period.

Assume now that the growth rate is positive and the rate of interest is equal to the growth rate, i.e. $r=g$. Moreover assume that we have the logarithmic utility function. Then the rate of growth of consumption equals the rate of interest. (It is the case which corresponds to a value $\mu=1$ ). Then the present value of consumption is constant and the same is true for the present value of wage income, as long as the person is part of the labour force. Again we find that the time point of gravity of discounted wage income is $\frac{\hat{a}}{2}$ and the time point of gravity of discounted consumption is $\frac{\hat{a}+\hat{b}}{2}$ so that the waiting period is $\frac{\hat{b}}{2}$, i.e. half the pension period. Given that these two special cases are quite different ones we can surmise that, generally, the pension period is highly important for the length of the waiting period.

I now continue with the more general model. For given time patterns of $w(t)$ and $c(t)$ we can find out how $Z$ changes as the rate of interest $r$ changes. We have

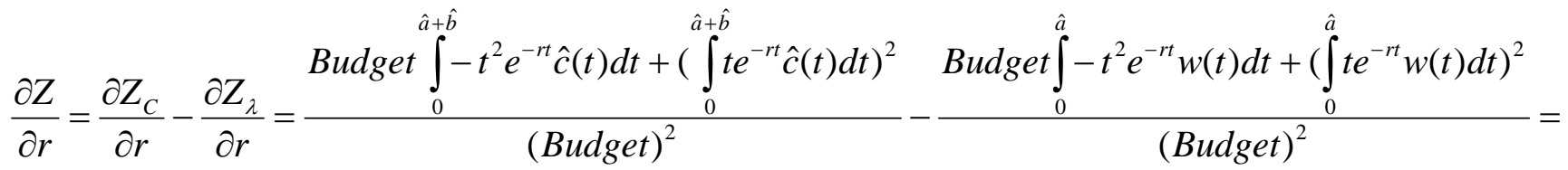

$$
\begin{aligned}
& =- \text { Variance }\left\{e^{-r t} \hat{c}(t)\right\}+\text { Variance }\left\{e^{-r t} w(t)\right\}
\end{aligned}
$$

Here "Variance\{ $\}$ ' is the variance of the inter-temporal density distribution of the present values of consumption and wage income respectively. It is the second central moment of the same distribution for which the "time point of gravity" is the first moment. We could have derived an analogous formula in the case of production. But there the different approach taken is more productive. But it is interesting and perhaps worth further thought that we expect the variance of labour inputs in the virtual factory to be larger than the variance of its consumption goods output whereas we expect the variance of consumption over the lifetime of a person to be larger than the variance of her labour supply. 
I now introduce substitution as a result of a change in the rate of interest. Here we use the specific time pattern of optimal consumption. We have

$U=\frac{1}{1-\mu} \int_{0}^{\hat{a}+\hat{b}} \hat{c}(t)^{1-\mu} d t$ with the optimal inter-temporal allocation (see above) $\hat{c}(t)=\hat{c}(0 ; \eta) e^{\frac{r}{\mu} t}=\hat{c}(0)^{\frac{\eta}{\mu} t}$. Now, observe that our substitution exercise works under the assumption that the shift in $\eta$ as a result of a shift in $r$ does not change utility (Remember from section VI above that $\eta(r)=r$ ). We look at the "compensated demand function". We know that in the optimal allocation the discounted value of marginal utility is the same across time. Thus a constant utility implies

$\int_{0}^{\hat{a}+\hat{b}} e^{-r t} \frac{\partial \hat{c}(t)}{\partial \eta} d t=0$ and thus the budget $\int_{0}^{\hat{a}+\hat{b}} e^{-r t} \hat{c}(t) d t$ remains constant as $\eta$ changes and as $r$ remains the same. We then can compute

$$
0=\int_{0}^{\hat{a}+\hat{b}} e^{-r t} \frac{\partial \hat{c}(t)}{\partial \eta} d t=\frac{d \hat{c}(0 ; \eta)}{d \eta} \int_{0}^{\hat{a}+\hat{b}} e^{-r t} e^{\frac{\eta}{\mu} t} d t+\hat{c}(0 ; \eta) \int_{0}^{\hat{a}+\hat{b}} \frac{t}{\mu} e^{-r t} e^{\frac{\eta}{\mu} t} d t
$$

which can be written

$$
\frac{d \hat{c}(0 ; \eta)}{d \eta}=-\hat{c}(0 ; \eta) \frac{\int_{0}^{\hat{a}+\hat{b}} e^{-r t} e^{\frac{\eta}{\mu} t} \frac{t}{\mu} d t}{\int_{0}^{\hat{a}+\hat{b}} e^{-r t} e^{\frac{\eta}{\mu} t} d t}=-\hat{c}(0 ; \eta) \frac{1}{\mu} Z_{C}
$$

We now can compute $\frac{\partial Z}{\partial \eta}=\frac{\partial Z_{C}}{\partial \eta}-\frac{\partial Z_{L}}{\partial \eta}=\frac{\partial Z_{C}}{\partial \eta}$. We have $\frac{\partial Z_{L}}{\partial \eta}=0$ because we assumed that labour supply does not change with relative inter-temporal prices. (It is not difficult to generalise the theory, although calibration becomes more cumbersome). Also the budget does not change, as utility remains the same with the same prices. So we get

$$
\frac{\partial Z}{\partial \eta}=\frac{\partial}{\partial \eta}\left(\frac{\int_{0}^{\hat{a}+\hat{b}} t e^{-r t} \hat{c}(t) d t}{\int_{0}^{\hat{a}+\hat{b}} e^{-r t} \hat{c}(t) d t}\right)=\frac{\int_{0}^{\hat{a}+\hat{b}} t e^{-r t} \frac{\partial \hat{c}(t)}{\partial \eta} d t}{\int_{0}^{\hat{a}+\hat{b}} e^{-r t} \hat{c}(t) d t}=\frac{\hat{c}(0 ; \eta) \int_{0}^{\hat{a}+\hat{b}} e^{-r t} \frac{t^{2}}{\mu} d t}{\text { Budget }}-\frac{1}{\mu}\left(Z_{C}\right)^{2}=\frac{1}{\mu} \operatorname{Variance}\left\{e^{-r t} \hat{c}(t)\right\}
$$

We then can compute the total derivative of $Z$ with respect to $r$

$$
\begin{gathered}
\left.\frac{d Z}{d r}=\frac{\partial Z}{\partial r}+\frac{\partial Z}{\partial \eta}=- \text { Variance }\left\{e^{-r t} \hat{c}(t)\right\}+\text { Variance }\left\{e^{-r t} w(t)\right\}+\frac{1}{\mu} \operatorname{Variance}^{-r t} \hat{c}(t)\right\} \\
\frac{d Z}{d r}=\frac{1-\mu}{\mu} \operatorname{Variance}\left\{e^{-r t} \hat{c}(t)\right\}+\text { Variance }\left\{e^{-r t} w(t)\right\}
\end{gathered}
$$

In this standard model I have ignored pure time preference. On the other hand I also have ignored the fact that a large fraction of the population bequest a large proportion of the wealth which they hold on average through their life-time. Some even accumulate wealth until they die. I do not claim that these two effects just cancel each other. But clearly they go into opposite directions. Since the social security system is a kind of "forced saving" I believe the inheritance effect to be stronger than the pure time preference effect. 
The standard model of inter-temporal allocation by households leads to the result that the waiting period reacts on changes in the steady state rate of interest in proportion to the variance of the inter-temporal distribution of labour supply and consumption demand.

\section{$\underline{\text { XIII Calibration for the consumption sector }}$}

The actual waiting period (including pension claims in the social security system) obviously is much larger than the actual period of production. The difference is explicit and implicit public debt in the OECD+China area, apart from a small net wealth position vis à vis the rest of the world which includes the rich oil exporting countries. The latter have a substantial net wealth position vis à vis the OECD+China area. Whereas explicit public debt is in the range of one to two years of annual (public and private) consumption implicit public debt is much larger, in particular due to obligations to actual and future social security pensioners. But there are other forms of implicit public debt as well, for example in the health care system, and for example (not easily calculable) implicit provisions for explicit or implicit guarantees in favour of bank creditors against default of their bank or for creditors of sovereign debtors like Greece, Portugal, Ireland etc. (The provisions are implicit public debt of the stronger states like Germany). It would thus not be outlandish to state that explicit and implicit government debt of the OECD+China area are around 7 years of annual public and private consumption. This would amount to about 5 years of annual GDP.

We then obtain an estimate of the waiting period of 12 years $=7$ years claims on government and 5 years of capital corresponding to the period of production which is 5 years. The benchmark state is an economy that grows at $2 \%$ per year, which together with a 5 years' period of production implies a net investment ratio of $10 \%$ of consumption. The annual real rate of interest of this (Golden Rule) benchmark state is $2 \%$.

Furthermore, empirical work on the elasticity of inter-temporal substitution, as defined in the literature (which in our model is $\frac{1}{\mu}$ ), indicates that it is substantially below unity (Guvenen (2006), also summarising earlier work). Thus I assume for calibration purposes that $\frac{1}{\mu}=\frac{1}{2}$ or $\mu=2$. This then indicates that

$$
\frac{d Z}{d r}=\frac{1-\mu}{\mu} \text { Variance }\left\{e^{-r t} \hat{c}(t)\right\}+\text { Variance }\left\{e^{-r t} w(t)\right\}=-\frac{1}{2} \operatorname{Variance}\left\{e^{-r t} \hat{c}(t)\right\}+\operatorname{Variance}\left\{e^{-r t} w(t)\right\}
$$

In the benchmark state we have $r=g=2 \%$ p.a. and thus $\left\{e^{-r t} w(t)\right\}$ is a rectangular distribution on the time interval $[0, a]$. The corresponding variance is equal to $\frac{1}{12} \hat{a}^{2}$. The present value of consumption (which grows at $\frac{r}{\mu}=1 \%$ ) declines by $1 \%$ per year. The corresponding variance is equal to approximately $\frac{1}{12.24}(\hat{a}+\hat{b})^{2}$.

Representative numbers for $\hat{a}$ and $\hat{b}$ in rich countries are 36 years and 18 years. The important point for our analysis is the ratio $\frac{\hat{b}}{\hat{a}}=\frac{1}{2}$. Using these numbers we get

$$
\text { Variance }\left\{e^{-r t} w(t)\right\}=108
$$




$$
\text { Variance }\left\{e^{-r t} \hat{c}(t)\right\} \approx 238
$$

Generally, as long the ratio $\frac{\hat{a}+\hat{b}}{\hat{a}}=\frac{3}{2}$ the ratio of the two variances is $\left(\frac{3}{2}\right)^{2}$ minus $2 \%=$ $\frac{9}{4}$ minus $2 \%$, and thus greater than 2 .

Calibration of the standard consumption model with retirement period $\hat{b}$ equal to half the active working life period $\hat{a}$ and with an inter-temporal elasticity of substitution (in the conventional meaning in the literature) of 0.5 leads to the result that

$$
\frac{d Z}{d r}=-\frac{1}{2} \text { Variance }\left\{e^{-r t} \hat{c}(t)\right\}+\text { Variance }\left\{e^{-r t} w(t)\right\}<0
$$

Therefore, as we move from the benchmark point of $r=2 \%$ to the point $r=0$ we can expect a rise in the waiting period, rather than a decline.

The result then is that at the rate of interest equal to zero we have the following inequalities

$$
Z \geq 12 \text { years and } T \leq 8 \text { years, hence } Z>T
$$

The same inequality of course holds at any interest rate between $0 \%$ and $2 \%$ p.a., as it also holds in the benchmark state of $2 \%$ p.a.

As discussed before, the standard model neglects pure time preference and it neglects the wish of people to leave wealth to their heirs. In my opinion the latter is more important than the former so that we should expect the same result if we include these two effects. The standard model also neglects the fact that people may have age specific preferences. In terms of payment out of their own pockets people tend to consume less in retirement than in active working life. On the other hand this tends to be compensated by the need for much more health care in old age, which, depending on the country, is paid by the government, a social security like system of health insurance, or by private insurers.

We then conclude that at a rate of interest of zero there is an overhang of the waiting period over the period of production:

$$
\underline{Z \geq 12} \text { years and } \underline{T \leq 8} \text { years, hence } \underline{Z>T} \text {. }
$$

The same inequality of course holds at any interest rate between $0 \%$ and $2 \%$ p.a., as it also holds in the benchmark state of an interest rate of $2 \%$ p.a.

\section{$\underline{\text { XIV The negative natural rate of interest }}$}

Our calibration has led to the result that for plausible values of $\psi$ and $\beta$ the period of production at an interest rate of zero is smaller than the waiting period. The calibration of the consumer parameters also indicates that the waiting period does not react strongly on a change in the steady state rate of interest. When I now try to compute the negative rate of interest at which period of production and waiting period coincide I can assume that the waiting period stays at 12 years. (Since the waiting period slightly rises as the rate of interest falls a correct computation would lead to even "more negative" natural rates of interest). Thus, using the formula for the period of production

$$
T=\frac{1}{(\psi-\beta-1)} \frac{1}{(r+a)}
$$

I compute the rate of interest at which the period of production is 12 years. The following table provides the results

Table 2: The natural rate of interest 


$\begin{array}{crr}\text { Psi } & \text { Beta } & \begin{array}{l}\text { natural rate } \\ \text { of interest }\end{array} \\ 4 & -0,5 & -1,00 \% \\ & 0 & -2,00 \% \\ & 1 & -4,00 \% \\ 3 & -0,5 & -3,00 \% \\ & 0 & -4,00 \% \\ & 1 & -10,00 \% \\ 2 & -0,5 & -6,00 \% \\ & 0 & -10,00 \%\end{array}$

My own best guess for the parameters is $2 \leq \psi \leq 3$ and $0 \geq \beta \geq-0.5$. This would imply a natural rate of interest between $-3 \%$ and $-10 \%$ per annum. The middle point of this range is $-6.5 \%$ per annum.

\section{$\underline{\text { XV A public debt inequality }}$}

As I pointed out in section XII, the period of production changes with the weighting system, as induced by the rate of interest $r$, in proportion to the difference between the time variance of the labour input path and of the consumption path. As a rule, we expect this difference to be positive - and thus, keeping $\theta$ constant, a rising interest rate leads to a rising period of production. The opposite is true for the waiting period. Here we expect the time variance of the consumption path of a person to be larger than the time variance of her labour supply. Thus, keeping $\eta$ constant, we expect the waiting period to decline as the rate of interest rises.

I now look at a zero interest steady state equilibrium, keeping the benchmark as before at $2 \%$ p.a. growth and $2 \%$ real rate of interest. Moreover, as derived by calibration above, I assume the waiting period to be larger than the period of production, because the natural rate of interest is negative. I then look at the equilibrium production method $\theta^{*}(0)$ and the equilibrium labour supply-consumption pattern $\eta^{*}\left(U^{*}(0) ; 0\right)$.

The next step is to look at these patterns $\theta^{*}(0)$ and $\eta^{*}(U *(0) ; 0)$ at the "false" prices induced by $r=g$. (They are "false" prices, because the patterns $\theta^{*}(0)$ and $\eta^{*}(U *(0) ; 0)$ have been induced by an interest rate equal to zero). At $r=g$ we have the equation

$$
Z=T+\hat{D}
$$

where $\hat{D}>0$ is the hypothetical debt period which would correspond to these "false" prices. This has been derived above in section VIII. Also, at these false prices, consumption per man year equals the wage rate paid $w=f\left(\theta^{*} ; g\right)$ by the production sector and the wage rate after tax received by wage earners $\hat{w}=\phi\left(\eta^{*} ; g\right)$.

For any rate of interest $r$ we then get the equations

$$
\begin{aligned}
& w(r)=w(g)+\int_{g}^{r} w^{\prime}(\rho) d \rho=\gamma(g)-\int_{g}^{r} T(\rho) w(\rho) d \rho \\
& \hat{w}(r)=\hat{w}(g)+\int_{g}^{r} \hat{w}^{\prime}(\rho) d \rho=\gamma(g)-\int_{g}^{r} Z(\rho) w(\rho) d \rho
\end{aligned}
$$

or, in logarithms, $\ln (w(r))=\ln (\gamma(g))-\int_{g}^{r} T(\rho) d \rho$ and $\ln (\hat{w}(r))=\ln (\gamma(g))-\int_{g}^{r} Z(\rho) d \rho$ 
Because we can assume $Z(g)>T(g)$ and $T^{\prime}(r) \geq 0$ and $Z^{\prime}(r) \leq 0$ we can derive the following: For $\rho \in[0, g] \quad$ we have $Z(\rho) \geq Z(g)>T(g) \geq T(\rho)$. It then follows $\ln (\hat{w}(0))-\ln (w(0)) \geq g(Z(g)-T(g))=g \hat{D}>0$. Because of $w(0)>\gamma(g)$ we then can infer $\hat{w}(0)-w(0) \geq g(Z(g)-T(g) \gamma(g)=g \hat{D} \gamma(g)$. On the other hand, we can compute private wealth $\hat{v}$ and capital tied in production $v$ by means of the equation $D \gamma(g)=\hat{v}-v=\frac{\hat{w}-w}{g}$ and thus we obtain the following inequality for the public debt period $D$

$$
D=\frac{\hat{v}-v}{\gamma(g)}=\frac{\hat{w}(0)-w(0)}{g \gamma(g)} \geq Z(g)-T(g)=\hat{D}
$$

Thus, the equilibrium public debt period corresponding to a real interest rate of zero is at least as large as the difference between the waiting period and the period of production as computed with a weighting system induced by an interest rate equal to the rate of growth.

\section{$\underline{\text { XVI The point-input-point output example }}$}

As a kind of appendix I describe the quite unrealistic special case of inter-temporal production, which is known in capital theory as the point-input-point-output model. The virtual factory here is characterised by a unit of labour input at some time point $\bar{t}<0$ and some output $Q$ of the consumption good at time zero. Thus, in this particular virtual factory we have a "flow" of labour inputs $\lambda(t)=0 ; t \neq \bar{t}$ and $\lambda(\bar{t})=1$; and we have a "flow" of consumption good output $q(t)=0 ; t \neq 0$, and $q(0)=Q$.

In this point-input-point-output model the period of production $T$ is of course equal to the time distance between the point labour input and the point consumption good output; hence $T=-\bar{t}$. The wage interest curve of this production technique then is given by the equation

$$
w=Q e^{-r T}
$$

The real wage is the present value of the consumption good output per man year. The value of the consumption good output has to be discounted back to the time when the wage has to be paid.

We may then assume that there exists the possibility to raise output per man year by raising the roundaboutness of production, i.e. by raising the period of production $T$. We stipulate a production function $Q=F(T)$. The choice of technique, i.e. the choice of the period of production then, as in section IV above, is such as to maximise the wage that can be paid. For given $r$ we differentiate the wage function $w=F(T) e^{-r T}$ with respect to $T$ and put the first derivative equal to zero. We get

$$
\begin{gathered}
\frac{\partial w}{\partial T}=F^{\prime}(T) e^{-r T}-r F(T) e^{-r T}=0 \\
\text { Hence } \frac{F^{\prime}(T)}{F(T)}=r
\end{gathered}
$$

The period of production is chosen so that the percentage marginal productivity of roundaboutness equals the rate of interest. In that case the market rate of interest is a signal for the percentage marginal productivity of roundaboutness.

Consumption per man year in this model is given by the equation

$$
\gamma(T ; g)=F(T) e^{-g T}
$$


It is output per unit of labour input $F(T)$ corrected for the delay between input and output: with a rising delay $T$ the output has to be distributed among more people. The maximum consumption per man year thus is not identical with maximum value of $F(T)$, but rather with the maximum value of $F(T) e^{-g T}$. This maximum is achieved if the market rate of interest is equal to the rate of growth: the Golden Rule.

The capital required in the steady state of a point-input-point-output economy growing at the rate $g$ then can be computed, using the formula derived for $v$. For a given period of production $T$ we obtain

$$
v=\frac{\gamma(T ; g)-w(T, r)}{r-g}=F(T) \frac{e^{-g T}-e^{-r T}}{r-g}=\gamma(T, g) \frac{1-e^{-(r-g) T}}{r-g}
$$

Applying l'Hôpital's rule we then obtain for $r=g$

$$
v=\gamma(T ; g) T=w(T ; g) T
$$

Capital requirement of the production sector in case that the market rate of interest equals the rate of growth is equal to the wage rate times the period of production.

My analysis in sections III and IV above then can be seen as a generalisation of the pointinput-point-output model. The latter has the advantage that we don't have to bother with a weighting system for the computation of the period of production $T$, because labour input is concentrated at one point and because consumption good output is concentrated at one point. Thus, to obtain some intuition about the period of production the point-input-point-output model is useful. But it is of course quite unrealistic. As I show above, if we are prepared to put up with the endogenous weighting system, we can generalise the results to more realistic models.

\section{$\underline{\text { Summing Up }}$}

The logic of this paper is based on a modernisation of Austrian capital theory as applied to a closed economy growing in a steady state. Here the philosophy is this: capital is time embodied in produced goods. In steady states, this philosophy works well as an aggregation device for an arbitrary number of distinct produced goods. The basic theorem of this approach (Section VII) is this: in a capital market equilibrium without public debt and hence in a general equilibrium without public debt the average period of production equals the average waiting period of households. Calibration of the parameters of the production sector and the consumption sector then leads to the result that the equilibrium risk free real rate of interest (Wicksell's "natural rate of interest") is negative for the OECD+China area. What distinguishes the twenty-first century from earlier times is the high life expectancy and the ensuing extensive average pension period. These characteristics are responsible for the high average waiting period. Only with a negative real rate of interest can the average period of production catch up with the high average waiting period.

Under price stability the risk free real rate of interest cannot become negative. Public debt causes the equilibrium risk free rate of interest to rise: Substantial public debt is required for the goal of price stability. We thus come to a different view of public debt: it is inconsistent with the goal of a zero public debt. This different view of public debt (even apart from "Keynesian" considerations) has been introduced by Samuelson already in the year 1958. My "Austrian" capital theoretic approach allows me to show that it is the relevant view for the twenty-first century. 


\section{$\underline{\text { List of mathematical symbols }}$}

$a$ a real scalar: parameter of the function determining the period of production as a function of $r$ under the assumption that the coefficient of inter-temporal substitution $\psi$ is constant. $\hat{a}$ a real scalar: parameter which gives the length of working time of the representative household.

$a_{i j}$ a real non-negative scalar: the quantity of input $i$ used up in the production of one unit of output $j$

$a_{j}=\left(a_{1 j}, a_{2 j}, \ldots . a_{n j}\right)$ an $n$-dimensional vector of real non-negative scalars: the input vector for one unit of output $j$

$A=\left(a_{1}, a_{2}, . . a_{n}\right)$ an $n$ times $n$ square matrix of real non-negative scalars: it consists of the $n$ different input vectors $a_{j}$ understood as column vectors. $A$ is also called the Leontief matrix.

$B$ a real scalar: parameter of the function determining the period of production as a function of $r$ under the assumption that the coefficient of inter-temporal substitution $\psi$ is constant.

$b_{j}$ a real non-negative scalar: the quantity of labour input used up in the production of one unit of output $j$

$b=\left(b_{1}, b_{2}, \ldots b_{n}\right)$ an $n$-dimensional vector of real non-negative scalars: the vector of labour input quantities for the different produced commodities.

$\hat{b}$ a real non-negative scalar: the pension period of the representative household $c_{i}$ a real non-negative scalar: the quantity of good $i$ that is consumed in the economy $c=\left(c_{1}, c_{2}, \ldots . c_{n}\right)$ a vector of real non-negative scalars: the consumption vector of the economy $C$ a real non-negative scalar: it is real total consumption in terms of the basket $\hat{q}$,i.e. we have $c=C \hat{q}$. That is, we assume that total consumption is proportional to the basket $\hat{q}$.

$\hat{c}(t)$ is a real non-negative scalar: it is the flow of consumption of the representative household in "numbers" of the consumption basket $\hat{q}$.

$g$ a real scalar: the rate of growth of the system. It has the dimension "1/year". It could be negative.

$h_{i j}$ a real non-negative scalar: the quantity of "machine" $i$ needed in the production of one unit of output $j$

$h_{j}=\left(h_{1 j}, h_{2 j}, \ldots h_{n j}\right)$ an $n$-dimensional vector of real non-negative scalars: the "machine" vector used for the production of one unit of output $j$

$H=\left(h_{1}, h_{2}, \ldots h_{n}\right)$ an $n$ times $n$ square matrix of real non-negative scalars: it consists of the $n$ different "machine" vectors $h_{j}$ understood as column vectors

$I$ : the $n$ times $n$ identity matrix

$i=1,2, \ldots . n \quad$ index of any one of the $n$ goods

$j=1,2, \ldots n \quad$ index of any one of the $n$ goods

$k$ a non-negative real scalar: an auxiliary variable which is a function of the chosen technique

$\theta$. In the special case of the Solow production function $k$ is the capital intensity of production.

$L$ a real non-negative scalar: the total labour input of the economy

$\hat{l}_{i}$ a real non-negative scalar: the Marxian labour content of commodity $i$ 
$\hat{l}=\left(\hat{l}_{1}, \hat{l}_{2} \ldots . \hat{l}_{n}\right)$ an $n$-dimensional vector of real non-negative scalars: the vector of Marxian labour contents of the different commodities.

$l_{j}(g)$ a real non-negative scalar: the generalised labour content of good $i$ as a function of the rate of growth of the system.

$l(g)=\left(l_{1}(g), l_{2}(g), \ldots . . l_{n}(g)\right)$ an $n$-dimensional vector of real non-negative scalars: the vector of generalised labour content of the different commodities.

$n \quad$ the number of different produced commodities in the economy

$p_{i}$ a real non-negative scalar: the price of commodity $j$

$p=\left(p_{1}, p_{2}, \ldots p_{n}\right)$ an $n$-dimensional vector of real non-negative scalars: the vector of

commodity prices

$\hat{q}=\left(\hat{q}_{1}, \hat{q}_{2}, \ldots \hat{q}_{n}\right)$ an $n$-dimensional vector of real non-negative scalars: the commodity basket used to define the real wage.

$q(t)=\left(q_{1}(t), q_{2}(t), \ldots q_{n}(t)\right)$ an $n$-dimensional vector of real non-negative scalars: the vector of consumption goods produced by the virtual factory as a function time.

$r$ a real scalar: the rate of interest. It has the dimension "1/year". It could be negative.

$s_{i j}$ a real non-negative scalar: the proportional time rate of "wear and tear" (depreciation) of machine $i$ in use for the production of output $j$. The coefficient $s_{i j}$ has the dimension " 1 / year".

$s_{j}=\left(s_{1 j}, s_{2 j}, \ldots s_{n j}\right)$ an $n$-dimensional vector of real non-negative scalars: the vector of time rates of "wear and tear" (depreciation) of machines in use for the production of one unit of output j

$S=\left(s_{1}, s_{2}, \ldots . s_{n}\right)$ an $n$ times $n$ square matrix of real non-negative scalars: it consists of the $n$ different wear and tear vectors for the production of the different outputs.

$T$ a real scalar: the average period of production.

$T(\theta, r)$ a real scalar: the average period of production as a function of the technique $\theta$ and the weighting system induced by $r$.

$t$ a real scalar: it represents time in a continuous time model.

$x_{i}$ a non-negative real scalar: the gross volume of production of commodity $i$

$x=\left(x_{1}, x_{2}, \ldots . x_{n}\right)$ an $n$-dimensional vector of non-negative real scalars: the production vector of the economy.

$v$ a real non-negative scalar: the value of capital per worker in the production sector.

$\hat{v}$ a real non-negative scalar: the value of capital per worker owned by households

$\tilde{w}$ a real non-negative scalar: the nominal wage rate

$w$ a real non-negative scalar: the real wage rate, i.e. the nominal wage rate divided by the

price of the basket $\hat{q}$

$\hat{w}$ a real non-negative scalar: the real wage rate "after taxes"

$w(r)$ the wage-interest curve

$w^{\prime}(r) \equiv \frac{d w}{d r}:$ the first derivative of the wage-interest curve

$w(r, \theta)$ :the wage rate as a function of the rate of interest $r$ and of the technique $\theta$

$w^{*}(r)=w(r, \theta(r)):$ the "envelope" of the different wage interest frontiers of the different techniques.

$z(t)=\left(z_{1}(t), z_{2}(t), \ldots z_{n}(t)\right)$ an $n$-dimensional vector of real non-negative scalars: the vector of gross outputs of the virtual factory. 
$\alpha(\theta)$ : a real positive scalar: as a function of the chosen technique $\theta$ the values of $\alpha$ and $\beta$ characterise the time flow of labour inputs in the virtual factory. The function $\alpha(\theta)$ does not show up in the computations for the period of production. There it is represented by the assumption of a constant coefficient of inter- temporal substitution.

$\beta$ :a real scalar: a parameter with a value $\beta>-1$ characterising the curvature of the wage interest curve $w(r)$ for a given technique $\theta$. The value $\beta=0$ corresponds to the Solow production function. We assume $\beta$ to be same for all $\theta \in$ Theta .

$\gamma:$ a real non-negative scalar: the number of commodity baskets which are consumed per unit of labour.

$\gamma(g)$ :the consumption-growth curve.

$\gamma(\theta ; g)$ : consumption per unit of labour as a function of the technique $\theta$ and the rate of growth $g$.

$\eta$ : an index for a pattern of labour supply consumption good demand of a household. For any given utility level $U$ the set $\operatorname{Eta}(U)$ is the set of available patterns $\eta$. Thus $\eta \in E t a(U)$ for some $U$.

$\eta(r)$ : the labour-consumption pattern implemented at a rate of interest $r$. We assume that labour-consumption patterns can be given indexes in such a way that the pattern used at rate of interest $r$ can be given the index $r$. Hence $\eta(r)=r$.

$\theta$ : an index for the available production techniques. The set of available techniques Theta . Thus $\theta \in$ Theta .

$\theta(r)$ : the technique in use as a function of the prevailing rate of interest $r$. We assume that production techniques can be given indexes in such a way that the technique used at rate of interest $r$ can be given the index $r$. Hence $\theta(r)=r$.

$\lambda(t)$ : a real non-negative scalar: the labour input of the virtual factory as a function of time. $\mu$ : a real non-negative scalar with $\mu \neq 1$ : a parameter describing the curvature of the utility function corresponding to the (constant) relative risk aversion.

$\rho$ a notional rate of interest between the rate of growth $g$ and the market rate of interest $r$

$\psi=\frac{\partial \frac{1}{T}}{\partial \theta}$ :a non-negative real number: it is the "coefficient of inter-temporal substitution"

\section{$\underline{\text { References }}$}

Arrow, Chenery, Minhas, Solow (1961); K.J. Arrow, H.B. Chenery, B.S. Minhas, R.M:Solow, Capital Labour Substitution and Economic Efficiency, Review of Economics and Statistics, 1961, 43, 225-250

Barbie, Hagedorn, Kaul (2004); Martin Barbie, Marcus Hagedorn, Ashok Kaul, On the Feasibility of Debt Ponzi Schemes - A Bond Portfolio Approach: Theory and Some Evidence, Working Paper, Department of Economics, University of Mainz , 2004, ashok.kaul@unimainz.de 
Blanchard and Weil (2001), Olivier Blanchard and Philippe Weil, Dynamic Efficiency, the Riskless Rate, and Debt Ponzi Games under Uncertainty, Advances in Macroeconomics, 1, 2001

Blanchard et al (2010); Blanchard, Olivier, Giovanni d'Arriccia, and Paolo Mauro, Rethinking Macroeconomic Policy, IMF Staff Position Note SPN/10/03, February 12, 2010, www.imf.org/external/pubs/ft/spn/2010/spn1003.pdf.

Böhm-Bawerk (1889), Eugen von Böhm-Bawerk, Positive Theorie des Kapitales, Jena 1889, Third edition Jena 1909.

Bruno (1969), Michael Bruno, Fundamental duality relations in the pure theory of capital and growth, Review of Economic Studies, 1969, 36, 39-55

Coase (1937); Ronald Coase, The Nature of the Firm, Economica 1937, 4, 386-405

Diamond (1965); Peter Diamond, National debt in a neoclassical growth model, American Economic Review, 1965, 55, 1126-1150

Feldstein (1977); Martin Feldstein, The surprising incidence of a tax on pure rent: a new answer to an old question, Journal of Political Economy 1977, 85, 349-60

Gale (1990); Douglas Gale, The efficient design of public debt, in R. Dornbush and M. Draghi (ed.), Public Debt Management: Theory and History, Cambridge University Press, 1990

Gesell (1916), Silvio Gesell, Die natürliche Wirtschaftsordnung durch Freiland und Freigeld, Les Hauts Geneveys 1916, 9 th edition Lauf, 1949

Guvenen (2006), Fatih Guvenen, Reconciling conflicting evidence on the elasticity of intertemporal substitution: A macroeconomic perspective, Journal of Monetary Economics, 2006, 53, 1451-1472

Homburg (1991); Stefan Homburg, Interest and growth in an economy with land, Canadian Journal of Economics, 1991, XXIV, 450-459

Kamstra and Shiller (2010); Mark J. Kamstra and Robert J. Shiller, Trills instead of T-Bills: Its time to replace parts of government debt with shares in GDP, The Economists'Voice, September 2010, 1-5, Berkeley Electronic Press; www.bepress.com/ev

Kotlikoff and Raffelhüschen (1999); Laurence J. Kotlikoff and Bernd Raffelhüschen, 1999. Generational Accounting around the Globe, American Economic Review, 1999, 89 (2), 161166

Marx (1967); Karl Marx, Das Kapital, Erstes Buch, Hamburg 1867

North, Wallis, Weingast (2009); Douglass C. North, John Joseph Wallis, Barry R. Weingast, Violence and Social Order, Cambridge University Press, 2009, 308 pages

Samuelson (1958); Paul Samuelson, An exact consumption-loan model of interest with and without the social contrivance of money, Journal of Political Economy, 1958, 66, 467-82 
Solow (1956); A contribution to the theory of economic growth, Quarterly Journal of Economics, 1956, 70, 65-94

Tirole (1985); Jean Tirole, Asset bubbles and overlapping generations, Econometrica 1985, 53, 1071-1100

von Neumann (1937); Johann von Neumann, Über ein ökonomisches Gleichungssystem und eine Verallgemeinerung des Brouwerschen Fixpunktsatzes, in Karl Menger (ed.), Ergebnisse eines mathematischen Kolloquiums, 1937, 8, 73-83. English Translation: John von Neumann, A model of general economic equilibrium, Review of Economic Studies, 1945, 13, 1-9.

von Weizsäcker (1963); Bemerkungen zu einem "Symposium" über Wachstumstheorie und Produktionsfunktionen, Kyklos, 1963 Vol. XVI, 438-457

von Weizsäcker (1971); C. Christian von Weizsäcker, Steady State Capital Theory, BerlinHeidelberg-New York 1971, 102 pages

von Weizsäcker \& Samuelson (1971); C. Christian von Weizsäcker and Paul A. Samuelson, A New Labor Theory of Value for Rational Planning Through Use of the Bourgeois Profit Rate, Proc.Nat.Acad.Sci.USA, 1971, Vol. 68, No 6, 1192-1194

von Weizsäcker (1977); C. Christian von Weizsäcker, Organic Composition of Capital and Average Period of Production, Revue d'Economie Politique, 1977, 198-231

von Weizsäcker (1979); C. Christian von Weizsäcker, Das eherne Zinsgesetz, Kyklos, 1979, XXXII, 270-282

Wicksell(1898); Knut Wicksell, Geldzins und Güterpreise, 1898 